Article

\title{
Preliminary Results of a New Auxiliary Mechatronic Near-Field Radar System to 3D Mammography for Early Detection of Breast Cancer ${ }^{\dagger}$
}

\author{
Ashkan Ghanbarzadeh Dagheyan ${ }^{1}$ (D), Ali Molaei ${ }^{2}$, Richard Obermeier ${ }^{2}$, \\ Andrew Westwood ${ }^{3}$, Aida Martinez ${ }^{4}$ and Jose Angel Martinez Lorenzo 1,2,* \\ 1 Mechanical Engineering Department, Northeastern University, Boston, MA 02115, USA; \\ ghanbarzadehdaghe.a@husky.neu.edu \\ 2 Electrical Engineering Department, Northeastern University, Boston, MA 02115, USA; \\ molaei.a@husky.neu.edu (A.M.); obermeier.r@husky.neu.edu (R.O.) \\ 3 Research Applications Specialist and Quantum Engineering Architect, Keysight Technologies, \\ 65 Alsun Drive, Hollis, NH 03049, USA; andrew.westwood@keysight.com \\ 4 Harvard Vanguard, Wellesley, MA 02481, USA; aida_martinez@atriushealth.org \\ * Correspondence: j.martinez-lorenzo@neu.edu; Tel.: +1-617-373-6835 \\ $+\quad$ This paper is an extended version of our paper published in Dagheyan, A.G.; Molaei, A.; Obermeier, R.; \\ Martinez-Lorenzo, J. Preliminary imaging results and SAR analysis of a microwave imaging system for early \\ breast cancer detection. In Proceedings of the IEEE 38th Annual International Conference of the Engineering \\ in Medicine and Biology Society (EMBC), Orlando, FL, USA, 16-20 August 2016.
}

Received: 3 November 2017; Accepted: 30 December 2017; Published: 25 January 2018

\begin{abstract}
Accurate and early detection of breast cancer is of high importance, as it is directly associated with the patients' overall well-being during treatment and their chances of survival. Uncertainties in current breast imaging methods can potentially cause two main problems: (1) missing newly formed or small tumors; and (2) false alarms, which could be a source of stress for patients. A recent study at the Massachusetts General Hospital (MGH) indicates that using Digital Breast Tomosynthesis (DBT) can reduce the number of false alarms, when compared to conventional mammography. Despite the image quality enhancement DBT provides, the accurate detection of cancerous masses is still limited by low radiological contrast (about 1\%) between the fibro-glandular tissue and affected tissue at X-ray frequencies. In a lower frequency region, at microwave frequencies, the contrast is comparatively higher (about 10\%) between the aforementioned tissues; yet, microwave imaging suffers from low spatial resolution. This work reviews conventional X-ray breast imaging and describes the preliminary results of a novel near-field radar imaging mechatronic system (NRIMS) that can be fused with the DBT, in a co-registered fashion, to combine the advantages of both modalities. The NRIMS consists of two antipodal Vivaldi antennas, an $\mathrm{XY}$ positioner, and an ethanol container, all of which are particularly designed based on the DBT physical specifications. In this paper, the independent performance of the NRIMS is assessed by (1) imaging a bearing ball immersed in sunflower oil and (2) computing the heat Specific Absorption Rate (SAR) due to the electromagnetic power transmitted into the breast. The preliminary results demonstrate that the system is capable of generating images of the ball. Furthermore, the SAR results show that the system complies with the standards set for human trials. As a result, a configuration based on this design might be suitable for use in realistic clinical applications.
\end{abstract}

Keywords: bimodal breast imaging; breast cancer detection; Near-field Radar Imaging; antipodal Vivaldi antenna 


\section{Introduction}

Based on the most recent statistical report from the United States Cancer Statistics (USCS) database in 2013, breast cancer holds the highest rate of incidence among American women [1]. Moreover, the same study reports that after lung and bronchus cancer, breast cancer possesses the highest count of mortality among female patients. In spite of the significant $34 \%$ decrease in breast cancer death rates, from 1990 to 2010 [2,3], much effort is still needed for more accurate diagnosis and effective treatment. The frequency of false-positive results from mammography, with a reported prevalence of 9.6\% [4], calls for the development of new techniques for cancer detection. Especially when false alarms could be a source of excessive short-term anxiety, and/or lead to multiple biopsies that some authors call unnecessary [5-7]. In the present paper, previous studies on breast cancer detection are collectively reviewed to address the necessity of enhancing the existing methods and devising novel techniques for more accurate detection of malignant tissues. This review is necessary, since it provides the engineering community a comprehensive description of the current methodologies for breast cancer screening. New findings suggest that multimodal screening systems, equipped with enhanced image quality and contrast, are capable of improving the accuracy of breast cancer detection. It is noteworthy to mention that prevention is another topic of interest that is predominantly overlooked despite its much lower inconvenience and cost for the patients. It has been estimated that $80 \%$ of all degenerative diseases, including cancer [8,9], and 30\% to 50\% of all cancer types [10] can be prevented with a comprehensive change in lifestyle and diet, thus reducing not only cancer mortality rates, but also incidence rates. This work only focuses on the main problems existing on current breast cancer detection systems, and it describe a set of potential solutions. Sections $2-4$ are dedicated to reviewing the past and current perspectives on breast imaging. Section 5 presents the original idea of using microwave imaging as a complementary modality to 3D X-ray imaging in detail.

\section{General Review on Mammography}

In this section, the contributions of mammography to breast cancer detection and survival rates are discussed. Also, the shortcomings of this modality and its impact on patients are reviewed. Different approaches have been proposed to compensate for these limitations, two of which will be introduced in the next two sections.

\subsection{Effect on Breast Cancer Survival Rate}

The objective of regular screening is to find cancerous tissues or tumors before their symptoms begin to manifest, according to the American Cancer Society [11]. The effective reduction in breast cancer morbidity throughout the years is attributed to both earlier detection by mammography and progress in cancer treatment [2]. The role of combined mammography and adjuvant therapy in decreasing the rate of death from breast cancer was backed up in a 25-year study form 1975 to 2000 in the USA [12]. Specifically, adjuvant therapy was more likely to be efficacious when the cancer was detected at earlier stages. Effectiveness of mammography was also reported in studies in England and Wales (2000) and Dutch (2003) as a turning point in the trend of death rates; however, the role of therapy in these works was not distinguishable from that of mammography $[13,14]$. Four consecutive reports in 1997, 2000, 2001, and 2007 collectively demonstrated a positive association between mammography and morbidity reduction in Northern Sweden [15-17]. With further investigation and excluding the impact of therapy, a 10-year study in 2005 showed a 25\% decrease in mortality, due to screening alone after the introduction of mammography in Copenhagen, Denmark [18]. Proponents of population-based mammography rely mostly on these promising results and are optimistic that, through regular screening, the chances of detecting tumors earlier would be higher. Annual mammography from the age of 40 is recommended for women by American Cancer Society, Society of Breast Imaging, and American College of Radiology, with the aim of detecting cancer in early stages [11,19]. Yet, World Health Organization (WHO) only recommends women to start regular screening from the age of 50-69 
every two years [20]. Contrary to the articles just reviewed, a number of new studies have cast doubt on the effectiveness of mammography in its entirety due to its possible risks and disadvantages [21-24]. One critique on these new studies, which challenge the positive role of mammography, can be found in [25].

\subsection{Main Drawbacks}

Though mammography has been able to enhance the possibility of early detection of breast cancer; false-positive (FP) and false-negative (FN) results, as well as over-diagnosis have raised some scientifically substantiated concerns (Figure 1). A research study in New England [26] showed a probability of $6.5 \%$ of false alarms among all investigated mammograms. This study reported that $23.8 \%$ of the participants received at least one false alert, and that the risk of getting an FP could be as high as 43.1\% after nine screening sessions [26]. In 2005, Castell and colleagues' study demonstrated a $10.6 \%$ prevalence of false alarm results in women (age range: $50-51$ ) entering a screening program, which was reduced to $3.8 \%$ in the second and following sessions. The cumulative risk of the FP results was estimated to be $32.4 \%$ in their report, implying that one out of three women in Spain could receive a false alert during 10 biennial mammography [27]. A recent study in 2011 reported that there is a $16.3 \%$ possibility of false alarm on the first mammography and $9.6 \%$ at the succeeding sessions in the USA [4]. The cumulative probability for a woman to experience an FP, starting at age of 40 (50), was 61.3\% $(61.3 \%)$ and $41.6 \%(42.0 \%)$ with annual and biannual screening, respectively. A patient who is recalled for further assessment must undergo common procedures such as needle biopsy, ultrasound imaging, or perhaps surgical biopsy, before the chance of malignancy is eliminated. Several factors could lead to an FP reading, such as age, family history, number of previous biopsies, current usage of estrogen, and one of the most influential, radiologists' tendency to interpret a mammogram as abnormal to avoid misdiagnosis [4,27]. The FN probability was estimated to be about $21 \%$ in film-screen mammography compared with 16\% in computer-aided detection [28]. An earlier study in 1996 reported that between $12.5 \%$ and $31.5 \%$ of mammograms resulted in FN outcomes, depending on age, follow-up duration, and family history [29]. Current research is mostly concentrated on enhancing the radiologists' diagnostic threshold, by introducing new methods to make image readings more confident and accurate.

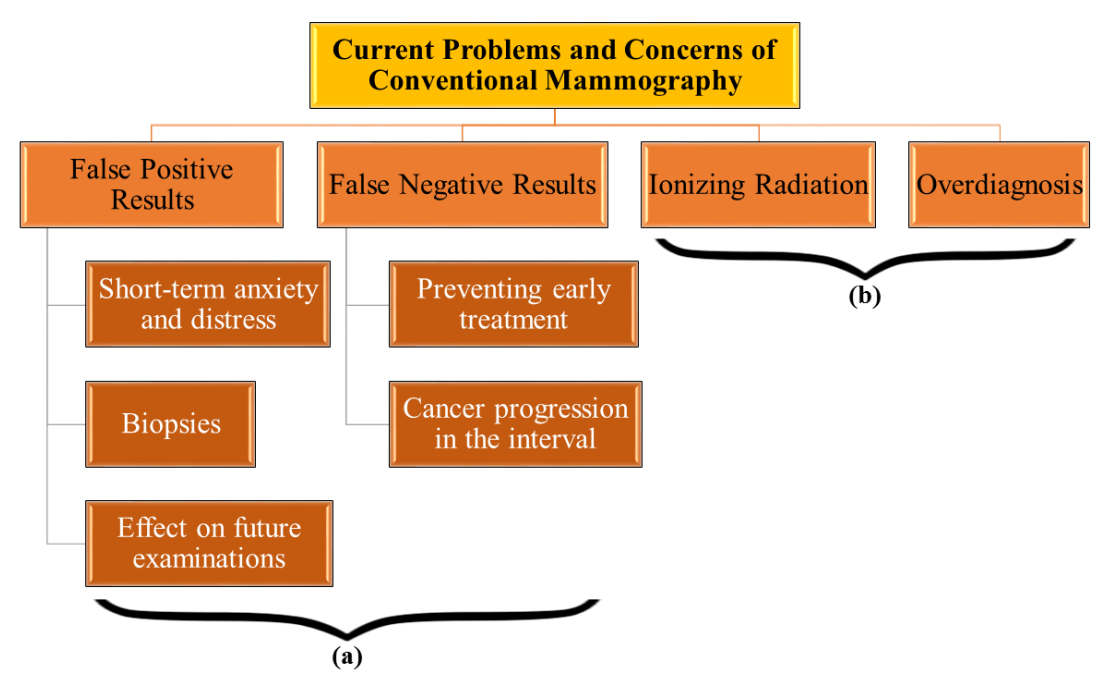

Figure 1. Current problems and concerns of mammography: (a) The problems that can be alleviated by the addition of a complementary imaging modality to mammography, (b) The concerns that are inherent to mammography and the addition of a complementary imaging system might not have a positive effect on them. 


\subsection{Effects of False-Positive Results}

Main consequences of the FP results have been reported as a noticeable increment in women's short-term anxiety, an alteration in their intention for future screening, and a boost in "false-positive biopsies" —as H. Welch and J. Passow have labeled them [30-32]. A Finnish study (2000) reported elevated levels of distress and anxiety about having breast cancer, accompanied by recurrent and lingering breast self-examinations (BSE), in patients who received false alarms [33]. Another study in Sweden (2003) reported similar results regarding BSE [34]. Although Marcia L. and others' study in 1999 didn't show a significant alteration in women's general screening behavior [35], a recent 2014 study was in agreement with the previous findings on an increase in women's short-term anxiety and their tendency to continue mammography [36]. McCann et al., reported a correlation between the risk of interval cancer (a cancer that starts between two successive mammograms) and the chance of FP results [37], and the reason why was speculated to be due to either hormone replacement therapy (HRT) or failure in the follow-up assessments that missed the tumor in the breast. In contrast to [36], McCann's report demonstrated a decrease in patients' intention for future attendance after getting an FP result.

In recent studies, FP results have been associated with an increased risk of developing breast cancer [38-40]. It was found that the risk is higher when an FP result is followed by biopsy than when only additional imaging is performed. Henderson et al. [38] speculated that the suspicious pattern that the radiologists detected in the first place, which turned out to be noncancerous, could be a marker of future cancerous activity and explain the extra risk. However, there are other factors that might contribute to the increased risk and need further research. These include tissue wounding [41-44], X-ray radiation for women who are carriers of BRCA1/2 mutations [45], and short- and long-term mental distress that is caused by the false results $[32,33,46]$ and has been associated with higher risk of breast [47] and other types of cancers [48] as well as with adverse effects on the immune system [49-52].

Financial costs of all the sequential tests after an FP result, and the time lag after which one's breast is declared cancer-free are also considerable. E. Lidbrink and colleagues estimated the entire cost of follow-up screenings and benign and surgical biopsies to be around $£ 250,000$ (about $\$ 394,000$ in that time. Rates based on 1995 currency values, from [53]) in the first round of screening and $£ 84,000$ (about $\$ 132,000$ in that time [53]) in the second round, per 1000 patients in 40-64 age span [54]. Moreover, it took almost 6 months for $73 \%$ of the patients in the first round and $64 \%$ of the patients in the second round to be declared free of cancer. For a minor portion of the studied population, this period lasted up to 22 months.

\section{Digital Breast Tomosynthesis}

\subsection{Novel Approaches in DBT}

Detecting tumors in dense breasts, which are those with $50 \%$ or more glandular tissue, is difficult using conventional X-ray systems. This needs to be addressed, since approximately $40 \%$ of women eligible for screening have a dense breast [55]. Digital Breast Tomosysthesis (DBT) utilizes full-field digital detectors and a rotating X-ray tube to scan the compressed breast $[25,56]$. The DBT, also known as 3D mammography, produces a 3D reconstruction of the breast tissue, enabling radiologists to extract and inspect any 2D layer of the breast at any given depth. Several algorithms such as Filtered Back Projection (FBP), Gaussian frequency blending (GFB), Maximum Likelihood Expectation Maximization Method (MLEM), and Simultaneous Algebraic Reconstruction Technique (SART) have been used to generate the 3D DBT reconstruction [57].

\subsection{DBT Contributions to Breast Cancer Detection}

Conventional mammography uses screen-film, with suitable resolution to detect micro-calcifications; however, its narrow dynamic range makes tumor visualization and detection difficult in dense regions of the breast [56]. On the other hand, full-field digital mammography (FFDM) utilizes detectors with 
wider dynamic range. Moreover, it provides two other advantages over screen-film mammography: the ability to manipulate images after screening and enhanced contrast between dense and fatty tissues. The accuracy of digital mammography was shown to be higher than that of the film-based one, particularly in women under the age of 50, patients with uniformly or extremely dense breasts, and premenopausal/perimenopausal women [58]. The DBT images of an FDA-approved breast phantom provided superior visibility of margins, lesions, and calcifications when compared to conventional mammography [59]. The DBT also provided better delineation of (1) boundaries of tumors, and (2) vessels around micro-calcifications, thus contributing to a better differentiation between benign and malignant tumors; and it used similar or less radiation exposure [59]. Teertstra et al. [60] also reported improved lesion detection using the DBT, and they suggested tomosynthesis as an additional screening system to conventional mammography for better examination of the breast. In the clinical setting, the combination of 2D and 3D mammography is preferred to and more commonly used than the DBT alone [56]. Bernardi et al. [61] reported an improved accuracy in breast imaging with combined 2D/3D mammography, which could lead to fewer FP results, and in turn, fewer follow-up biopsies. In accordance with this observation, Gur and his colleagues [62] found an average of $10 \%$ reduction in false alerts when a 2D/3D setup was used. Furthermore, in the recent 2014 study, Houssami et al. [63] reported an increase in the rate of true-positive results and higher sensitivity using the DBT as an additional diagnostic tool to the 2D mammography. In Bernardi's subsequent 2014 study [64], meaningful improvement was found in radiologists' true-positive evaluation-from $60 \%$ in $2 \mathrm{D}$ to $87 \%$ in $2 \mathrm{D} / 3 \mathrm{D}$. Moreover, $7 \%$ increase in sensitivity for dense breasts and $9 \%$ increase in specificity for all study groups were the results of 2D screening plus the DBT in TOMMY trial in the UK [65]. Based on these studies, it is concluded that the DBT has enhanced breast imaging performance; still, there is much room for progress in minimizing the FP and FN results. It should be noted that the publication bias and the funding bias were not investigated in the reviewed studies concerning the DBT.

\section{Microwave Breast Imaging}

Inasmuch as more contrast exists between the cancerous and fibro-glandular tissues in microwave frequencies [66], microwave imaging is a suitable candidate for further investigations as an addition to $2 \mathrm{D} / 3 \mathrm{D}$ mammography. In microwave imaging of the breast, the retrieval of dielectric properties-permittivity and conductivity, whose values differ relatively largely between the aforementioned tissues-is the primary goal. In this regard, another modality of interest is millimeter-wave imaging that can combine high resolution with high contrast and has been recently investigated for breast cancer detection $[67,68]$. This study focuses on microwave imaging in the near field and introduces a potential solution (Section 5) to alleviate the limited resolution problem and other challenges that exist at microwave frequencies. An extensive review of breast microwave imaging systems by Nikolova, from the early works to the recent advances, can be found in [69]. In this section, a brief overview of microwave imaging is presented and some initial studies concerning its applications are reviewed.

\subsection{Background}

Imaging in the microwave spectrum is of particular interest since the permittivity and conductivity values between healthy and cancerous mammary tissues differ largely in this frequency band. In the large-scale study by Lazebnik et al. [70], it was found that the electrical properties discrepancy between normal tissues and malignancies can be as high as 10:1 for adipose-dominant, and as low as $10 \%$ for fibro-glandular-dominant regions in the breast. Though the latter appears to be low, it is still meaningfully higher than the contrast $(1 \%)$ that has been observed in X-ray frequencies between the same types of tissues [66]. One should note that in vivo experiments have demonstrated larger permittivity values for healthy tissues than, and subsequently different contrast ratios from, those obtained in the previous ex vivo tests [71,72]. In other words, the contrast is shown to be lower 
in the in vivo experiments than that in the ex vivo ones; yet, it is still higher than the contrast that is $\mathrm{X}$-ray frequencies.

In addition to improving the contrast between the aforementioned tissues, microwaves can feasibly penetrate the breast with its largely fatty content and limited volume [73]. Several articles in literature have been dedicated to develop practical algorithms for microwave imaging from years ago until recently. Iterative numerical methods based on Newton-Kantorovish, Levenberg-Marquardt, and conjugate gradient least square procedures [74-76]; finite element, finite difference time-domain [77-79], and finite difference frequency-domain approaches [80-83]; as well as ensemble empirical mode decomposition [84], to name a few, have been proposed for solving microwave imaging problems. There is a number of physical and technical challenges in microwave imaging approaches as well. Among these, limited resolution, tissue loss, motion and heterogeneity, and difficulties in forward modeling can be mentioned [69].

\subsection{Breast Microwave Imaging at Experimental and Simulation Stage}

Microwave imaging for breast cancer detection has been investigated in both far- and near-field configurations. Several recent studies have reported the feasibility of holographic far-field imaging (HFI) for clinical applications [85,86]. In 2013, Wang et al., presented the 2D images of a breast phantom, both in simulation and experiment, using the holographic far-field approach [86]. Later, they demonstrated the imaging results of 3D objects with high resolution using the same technique $[87,88]$. Paz et al., showed that a setup with random spatial distribution of the antennas performs better than a layout with uniform antenna distribution and avoids the generation of replicas in the image reconstructed by the HFI [89]. Near-field radar imaging (NRI) systems, due to their generally easy implementation in a limited space, have attracted more interest for breast cancer imaging during the last decades [90-98]. This study also focuses on a compact NRI system.

Among the early works in NRI, that of Meaney et al., in 2000 is a pioneer in clinical implementations [72]. They introduced a physical layout for microwave imaging from 0.3 to $1 \mathrm{GHz}$. Their clinical prototype involved a liquid container in which the breast could be in pendant position and microwave antennas illuminated the tissue through saline as a matching liquid. In this trial, human subjects were examined in sessions lasting 10-15 min for each breast, by a tomographic approach starting from the chest and ending at the nipple. The results had low resolution in the permittivity and conductivity images as expected, but they provided valuable insight into the potentiality of the NRI in practice. A later study from the same research group [83] reported a good agreement between images obtained from microwave imaging and the MRI on human subjects with negative mammograms (cancer-free) as well as phantoms. The images of layered phantoms of various shapes and sizes showed satisfactory contrast without using prior information, indicating the robustness of the imaging algorithm.

In terms of array design, many experimental and fabrication studies, similar to that of Meaney, Golnabi and others $[83,99,100]$, used a cylindrical arrangement of the antennas that surrounded a target or a breast hanging freely in the coupling medium [101-103]. Klemm et al., however, introduced a hemispherical microwave antenna array to conform with the shape of the breast and presented the imaging results of different breast phantoms using delay-and-sum and data-adaptive beam-forming [104]. Further, they tested the system for low-contrast scenarios [105] and carried out small-scale clinical experiments [106]. The idea of conformal or wearable sensors for breast cancer imaging was also pursued by Bahramiabarghouei et al. [107], via designing a flexible antenna array, and Rahman et al. [97], via fabricating antennas using a flexible material. Other flexible sensor designs can be found in $[87,108,109]$.

In addition, microwave imaging via space-time (MIST) beam-forming has been implemented in 2D and 3D layouts [110]. In this technique, an ultra-wideband (UWB) antenna array transmits the waves and subsequently a beamformer images the backscattered signal energy as a function of position. In lieu of reconstructing the whole map of breast through an inverse algorithm, the UWB radar only manifests 
regions of high backscattered energy levels, i.e., malignancies. Then, the data-adaptive algorithm effectively removes dominant backscatter in the skin-breast interface to minimize its overshadowing effect. Both 2D and 3D simulations on breast phantoms were encouraging and robust. More recent studies include those that employ microwave radar-based data as prior knowledge to microwave tomography [111], use NRI for axillary imaging as an aid to breast tumor detection [112], and monitor tumor growth status during neoadjuvant chemotherapy [113].

\section{A Bimodal System: DBT Plus NRI}

After reviewing the advantages and shortcomings of NRI and X-ray systems, it appears that a dual operating system of microwave and X-ray imaging could leverage the advantages of each approach and simultaneously compensate for some of their individual drawbacks. Two recent studies have evaluated the applicability of this idea by software simulations using fat distribution maps from the DBT [114,115]. This paper is an extension of [116]; and, at hand, it proposes an ultra-wideband NRI mechatronic system (NRIMS) that serves as a complementary scanning machine to the DBT to result in a bimodal hybrid imaging system. The fundamental idea behind the system is as follows (Figure 2): firstly, the DBT scans the breast with X-ray independently and collects the data required to reconstruct the 3D image; sequentially, NRIMS scans the tissue under compression one more time with microwaves $(1-3 \mathrm{GHz})$ in a planar motion over the breast; next, the DBT image is used as a priori information by the microwave imaging algorithm in order to estimate the heterogeneous healthy tissue distribution in the breast. Here, the preliminary results of the NRIMS working in a standalone mode are presented for the sake of assessing its independent performance in a simple experiment. In the proceeding subsections, each part of the NRIMS is described $[117,118]$.
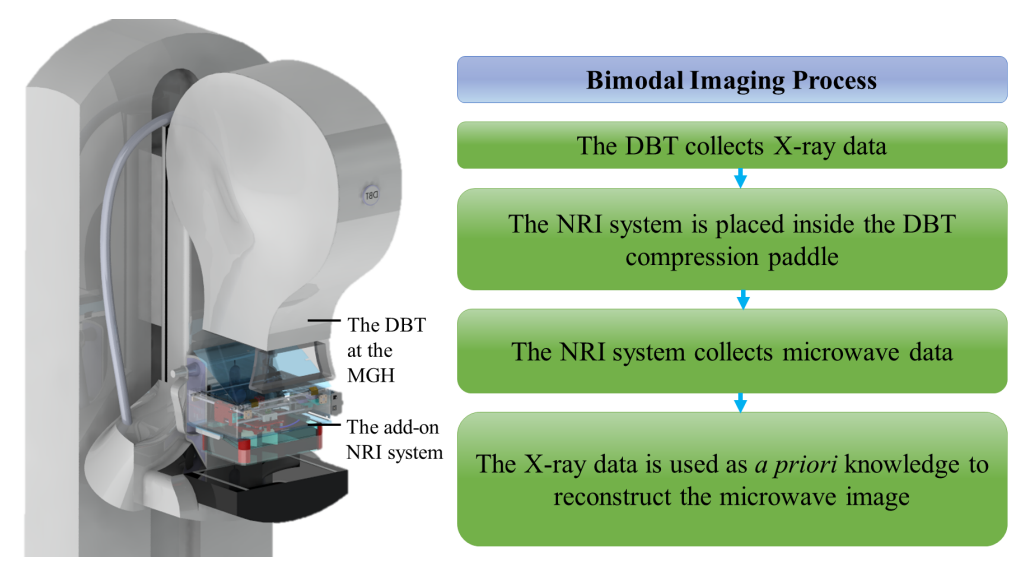

Figure 2. The bimodal imaging process using the DBT and NRI.

\subsection{Antipodal Vivaldi Antennas}

Vivaldi antennas are compact, planar, and easy to fabricate [119]. Hence, they are a suitable candidate for an add-on NRI system. Nevertheless, these antennas, in general, require a balun to convert the microstrip into a strip-line and this eventually limits their bandwidth. One solution to overcome this restriction is to use Antipodal Vivaldi Antennas (AVAs), which have direct feeding microstrip lines and, at the same time, maintain the advantages of Vivaldi antennas. The AVAs presented in this work are designed and fabricated to radiate in a coupling medium instead of air, so that the electromagnetic energy coupled into the breast is enhanced. Using a coupling liquid with a high dielectric constant decreases each dimension of the antenna by a factor of $1 / \sqrt{\epsilon_{r}}$, with $\epsilon_{r}$ being the relative permittivity of the liquid, which in turn enables the use of an array of antennas in a limited space. Such technique, however, requires a supportive substrate that has a high dielectric constant. A 2-mm ceramic substrate (T-Ceram, E-37) with a permittivity of about 37 meets this requirement. Figure 3 demonstrates the design parameters of an AVA as well as a photo of two fabricated AVAs. 
The parametric curves $y_{a}, y_{t}$, and $y_{f}$ shown in the figure are of exponential nature and follow the equations below [120]:

$$
\begin{gathered}
y_{i}= \pm\left(A_{i} e^{P_{i}\left(x-B_{i}\right)}+C_{i}\right) \\
C_{i}=\frac{y_{i 1} e^{P_{i} x_{i 2}}-y_{i 2} e^{P_{i} x_{i 1}}}{e^{P_{i} x_{i 2}}-e^{P_{i} x_{i 1}}} \\
A_{i}=\frac{y_{i 1}-y_{i 2}}{e^{P_{i}\left(x_{i 1}-B_{i}\right)}-e^{P_{i}\left(x_{i 2}-B_{i}\right)}}
\end{gathered}
$$

in which $i$ can be substituted with $a$, $t$, or $f$ to obtain $y_{a}, y_{t}$, or $y_{f}$, respectively. The constants $A_{i}, B_{i}, C_{i}$, and $P_{i}$ for each equation can be found in Table 1.
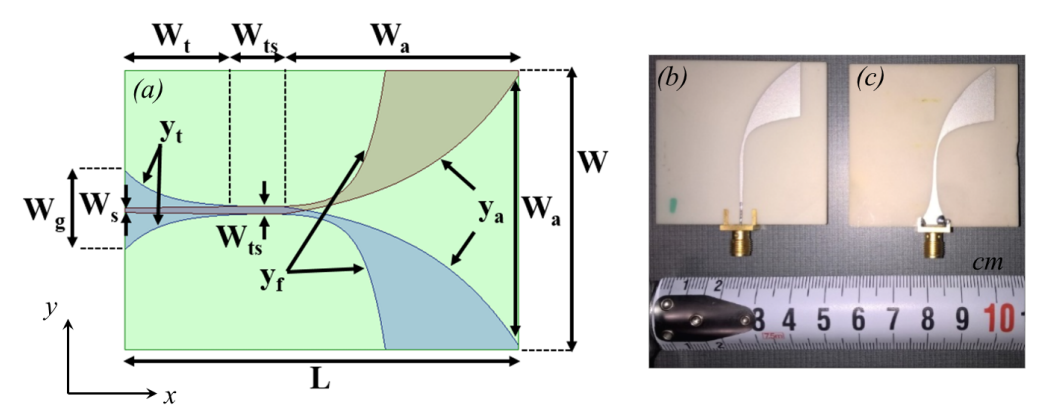

Figure 3. (a) The geometric design parameters of an AVA. The curves denoted by $y_{a}, y_{t}$, and $y_{f}$ are exponential. This transparent view of the antenna shows the curves on the front and back of the antenna (b) the fabricated antennas, signal side (left), and (c) ground side (right) [121].

Table 1. The parameters in the curve equations of the AVA.

\begin{tabular}{cccccc}
\hline$i$ & $y_{i}(x)$ & $\mathbf{A}_{i}$ & $\mathbf{B}_{i}$ & $\mathbf{C}_{i}$ & $\mathbf{P}_{i}$ \\
\hline$t$ & $y_{t}$ & $\frac{W_{t s}-W_{g}}{2\left(e_{t} L_{t}-1\right)}$ & 0 & $\frac{W_{g}}{2}-A_{t}$ & $P_{t}$ \\
$f$ & $y_{f}$ & $A_{f}$ & $W_{t}+W_{t s}$ & $\frac{W_{t s}}{2}-A_{f}$ & $P_{f}$ \\
$a$ & $y_{a}$ & $\frac{W_{t s}+W_{a}}{2\left(e^{P_{a}} L_{a}-1\right)}$ & $W_{t}+W_{t s}$ & $-\frac{W_{t s}}{2}-A_{f}$ & $P_{a}$ \\
\hline
\end{tabular}

For the antennas built, the numerical values of the parameters given in Table 1 are as follows: $W=30, W_{g}=2.06, W_{a}=25.42, W_{t s}=0.29, W_{s}=0.025, L_{t}=8.40, L_{t s}=1.03, L_{a}=26.54$, all in millimeters; and $P_{t}=-1.04, P_{f}=0.94$, and $P_{a}=0.1$. More details about these antennas can be found in [122].

\subsection{Selecting the Coupling Liquid}

According to Lazbnik and colleagues' comprehensive study [71], the dielectric constant of the breast can vary from as low as 4 to as high as 67 over $1-3 \mathrm{GHz}$, contingent upon its adipose content. In general, in healthy tissues, higher adipose percentage was associated with a lower averaged dielectric constant, and lower adipose content, or higher glandular and fibro-connective content, resulted in higher averaged dielectric constant. Rappaport [123] calculated the optimum dielectric constant for a presumed bolus liquid over 0.4 to $10 \mathrm{GHz}$, aimed at minimizing the reflection coefficient magnitude. The objective was to find the permittivity and conductivity values of a bolus liquid that enhanced the amount of energy coupled into the breast. It was shown that for 1.3, 2, and $3 \mathrm{GHz}$, the optimum relative permittivity was about $17.5,32.5$, and 65 , respectively. Furthermore, as mentioned in the previous subsection, the dielectric constant of the selected ceramic was around 37. Considering these facts, and noticing that dielectric constant relaxation plots generally display a constant and then a decreasing trait as frequency goes up, the search for a suitable coupling 
liquid was limited to liquids whose dielectric constant were between 15 and 35 in $1.5-3 \mathrm{GHz}$ range. The electrical properties of numerous liquids have been documented in the literature over a wide span of frequencies at $25{ }^{\circ} \mathrm{C}$; hence, there were many cases to look into to find the desirable complex permittivity. As the first attempt, permittivity and conductivity behavior of binary aqueous mixtures of sodium chloride [124], ethanol [125], DMSO [126], DESO [127], glycine [128], ethylene glycol oligomer [129], 2-butoxyethanol [130], butyric acid [131], and 2-methoxyethanol [132] were reviewed. Later, other chemical compounds or their non-aqueous mixtures were also considered; among which methanol, 1-propanol, 2-propanol [133], dialkyl carbonates [134], 1-Hexanol/1-propenol [135], lithium salts/dimethyl carbonate [136], ethylene glycol - dimethyl sulfoxide [137], morpholine/n-butanol, and C16-ether-PN6-1ecith/methanol [131] can be named. Last efforts constituted reviewing a Ketone-like chemical, Dimethylketone (DMK), in mixture with 2-Butoxyethanol (2-BE) [138] and corn syrup [139]. Most liquids were ruled out based on the following criteria:

(i) The liquid must have a permittivity between that of the ceramic used as the antenna substrate and that of the breast $\left(\epsilon_{\text {breast }}<\epsilon_{\text {liquid }}<\epsilon_{\text {ceramic }}\right)$.

(ii) The liquid must be non-toxic, non-carcinogenic, chemically stable, and possess relatively low viscosity and evaporation rate at the room temperature.

(iii) The AVAs must demonstrate acceptable performance in simulations using the selected liquid's characteristics. The factors that need to be considered in the performance quality evaluation are the following: high directivity and a return loss above $10 \mathrm{~dB}$.

Figure 4 illustrates the permittivity and conductivity plots for four different liquids as examples among those that were initially considered. These liquids met some of the criteria mentioned above, yet, eventually three of them were excluded due to high viscosity (corn syrup), higher dielectric constant than antennas' substrate (DMSO), and possible carcinogenicity (methanol).

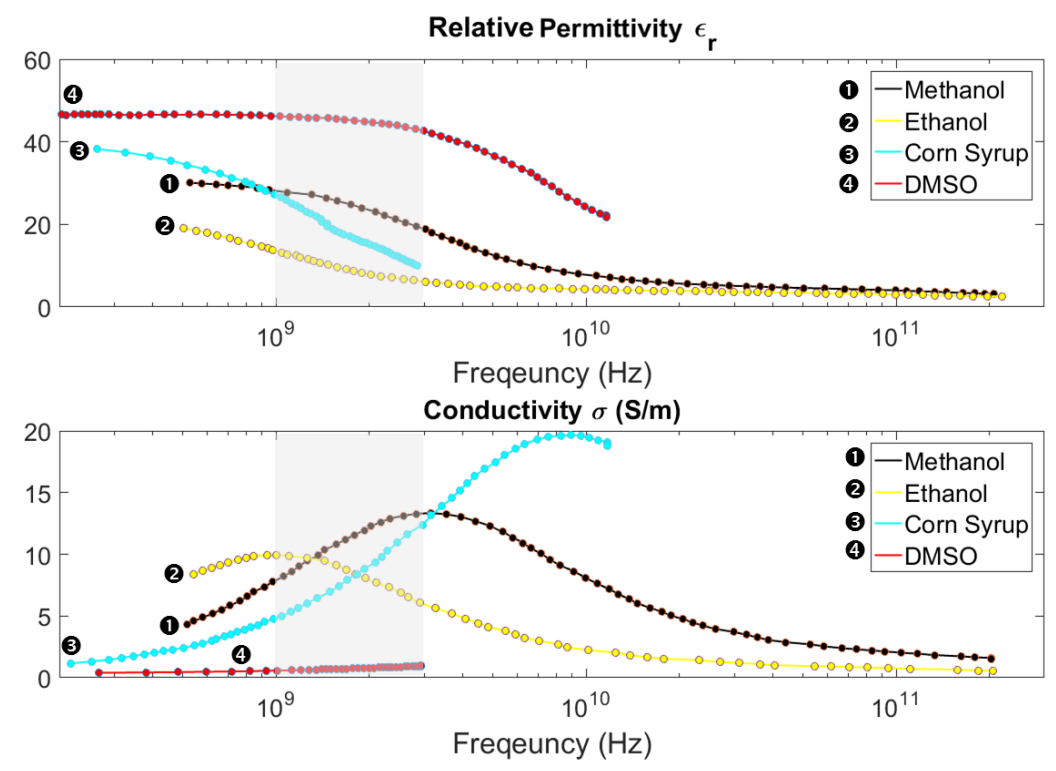

Figure 4. Relative permittivity and conductivity of four selected liquids. The frequency range of the system presented here $(1-3 \mathrm{GHz})$ is shaded in gray. Data is taken from [125,126,133,139], severally.

In the final analysis ethanol was selected, since it met almost all the conditions and was easily available for laboratory use. Previously, in [122] the performance of the designed AVA in a customized bolus liquid was presented. Here, Figure 5 illustrates how one AVA performs in ethanol, based on the liquid model given in [140] and using ANSYS HFSS software. It shows that the waves have 
penetrated the acrylic and polycarbonate plastic layer (bottom of the liquid container plus the paddle) into the breast. Also, the directivity of the AVAs in the 1-2.5 GHz frequency span is acceptable. In the test-bed presented in this work, only two antennas (transmitter/receiver) were built, for which the s-parameters and mutual coupling behavior inside ethanol can be found in [140].

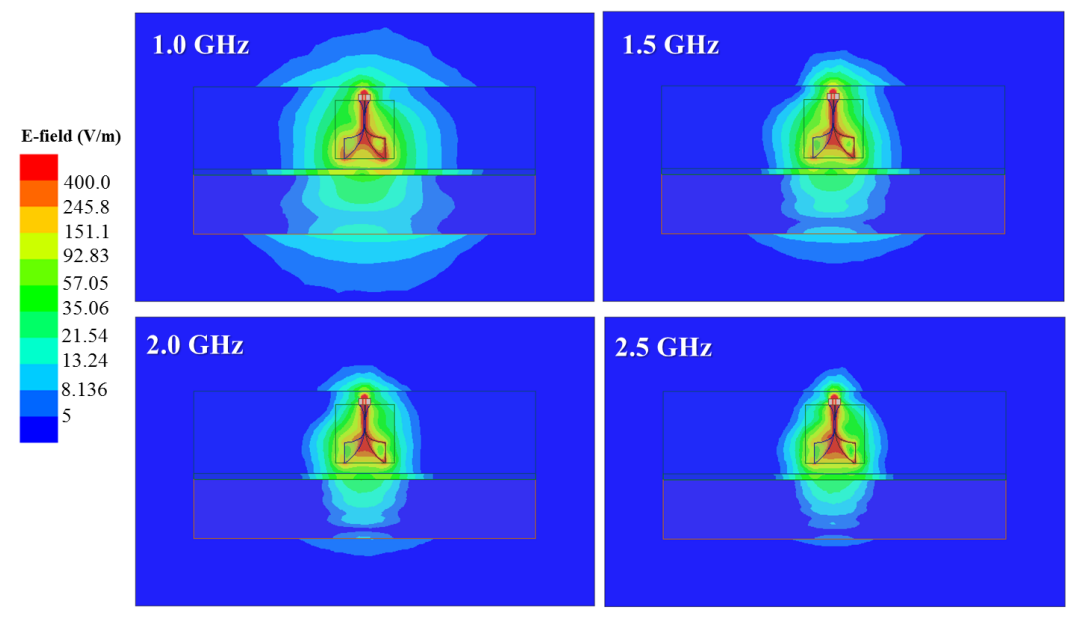

Figure 5. The absolute value of the electric field (E) induced by one AVA inside ethanol. The container and compression paddle are accounted for by a simplified model in HFSS. The top and bottom blocks represent the ethanol volume and the compressed breast, respectively. A thin layer of plastic (acrylic, $6 \mathrm{~mm}$ ) is placed in between the blocks.

\subsection{Mechatronic System}

Physical Layout. For the test-bed, the antenna set needs to be moved in a predefined 2D path to collect the data over a horizontal plane. To achieve this purpose, a belt-driven mechanical layout was designed based on the open source 3D printer MAKERBOT Replicator. In this simple configuration, two stepper motors were mounted; one in a stationary position, and the other one on two steel bars, equipped with linear bearings, to make the planar motion possible. The fixed motor moved a secondary structure on the $\mathrm{Y}$ axis, including the other motor and the antenna set. The sliding motor moved the antennas on the $X$ axis. The size and geometric qualities of the box containing all the mechanical parts were mainly restricted by General Electric DBT's large compression paddle dimensions. Given these dimensions, two acrylic boxes were simply built, one on the top, holding the described XY actuator, and one on the bottom, serving as a liquid container. The bottom part was to fit into the paddle, and stand directly over the compressed breast area (Figure 6a-d).

An Arduino UNO board and two Big Easy Drivers were used to actuate the motors. A 12 V/5 A power supply was employed to feed the two motors with an average amperage of $0.6 \mathrm{~A}$ (each) under the load, and it was wired via Arduino power jack to the two driver's power input (Figure 6f-g). To ensure that the box safely contains the coupling liquid, firstly, the bottom segment was sealed with a silicon-based sealant that was specifically designed for plastics (General Electric) and secondly, a lid with hinges was placed over the whole assemblage to constrain ethanol's evaporation rate. Finally, small holes were made on the lid for the antennas' cables and electronic wires to pass through.

Programming. LabVIEW programming software was used to control the mechatronic system in sync with a vector network analyzer (KEYSIGHT, PNA-X N5242A). In order to establish the connection between Ardunio and LabVIEW, LabVIEW Interface for Arduino (LIFA) was installed on a Windows 10 workstation, and its already existing Stepper Motor Library was used to set the motion characteristics of the two motors. Motors were set to move at a constant speed of 2000 steps/s in each segment of the path, whose schematic is depicted in Figure 7. As can be observed, at any time in the motion, only one motor moves and the other one stays inactive. 


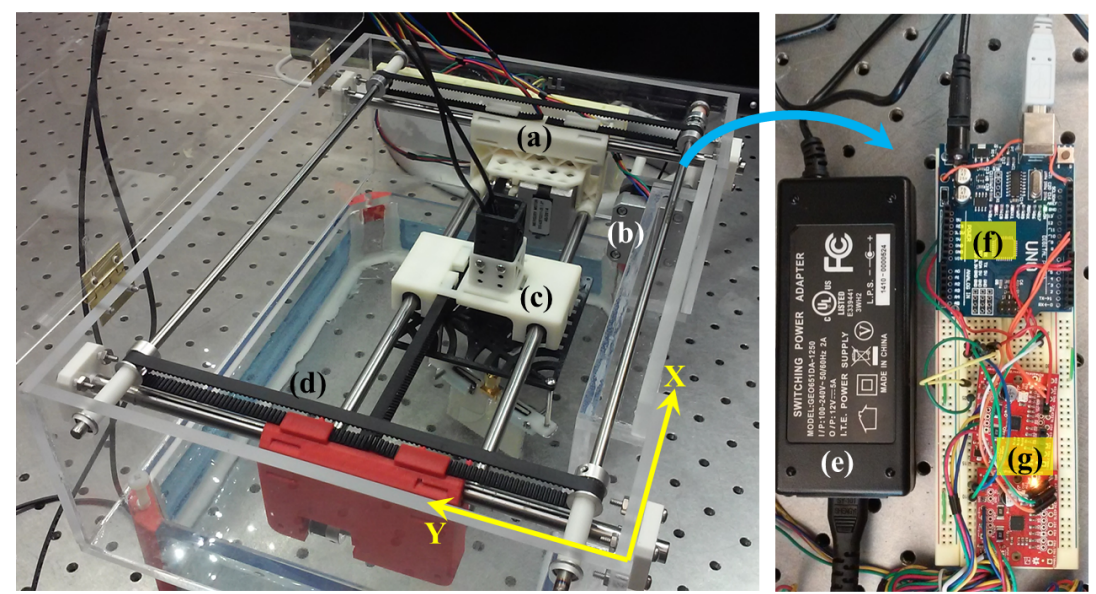

Figure 6. Mechatronic System: (a) Sliding motor and its holder, (b) fixed motor, (c) antenna holder, (d) belt-driven motion, (e) 12V/5A power supply for motors, (f) Arduino UNO, (g) Two Big Easy Drivers.

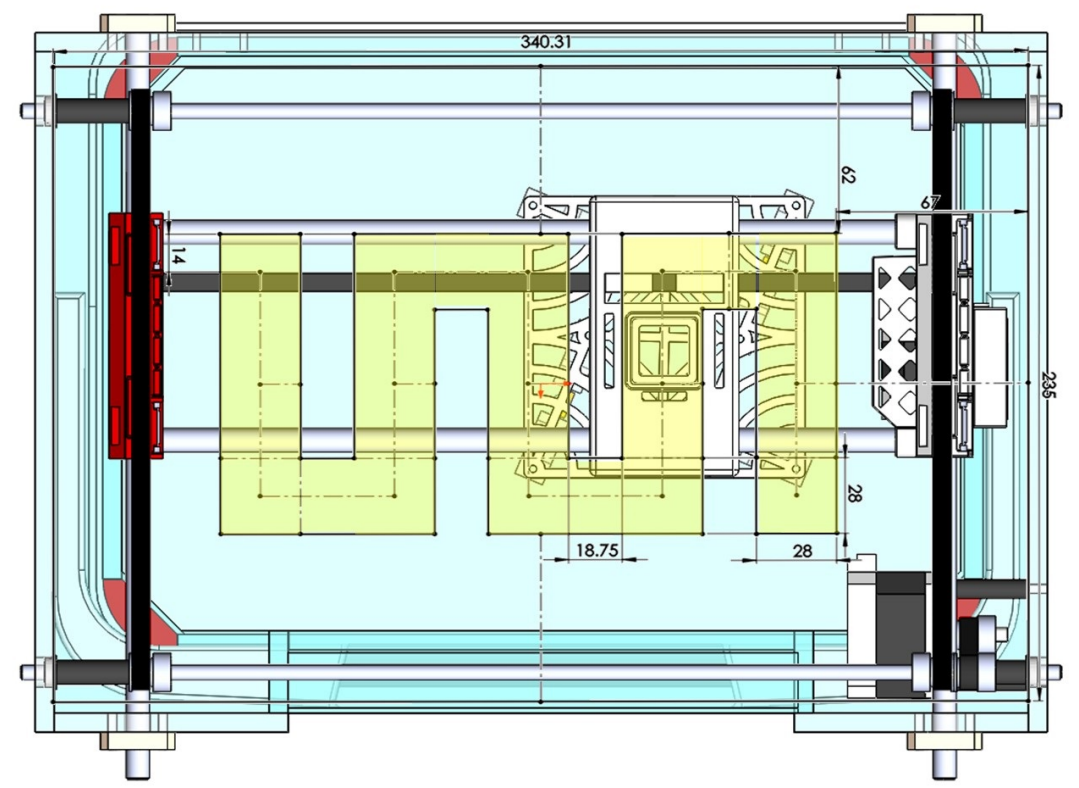

Figure 7. Schematic of the forward path the antenna set follows over the breast (the system top view, dimensions are in $\mathrm{mm}$ ).

Next, LabVIEW NI VISA MAX and Keysight IO Libraries Suite 17.1 were employed to configure the connection between the PNA-X and the PC, using a an Ethernet cable. Having both the PNA-X and two stepper motors connected to the host PC, a LabVIEW Virtual Instrument (VI) was developed to time the data acquisition and the mechanical motion. Since the motors and the control action from the drivers were of adequate precision, instead of using a position-sensor feedback solution, an open-loop one was adopted. Two approaches were possible to automate the system with that solution. One would be generating a Trigger Out signal from the PNA, after the s-parameter measurement on a specific position was done, and using it to command one of the motors to start moving to the next position. The other, and the less complex, method was to use time delays in order of milliseconds, one after the completion of motor motion (50 ms) and one after the data acquisition command ( $20 \mathrm{~ms})$, to make sure each task was completed before moving forward to the next. Since both commands were executed relatively fast (70 ms delay in each step), the second method was selected. The overall travel and acquisition time was about $15 \mathrm{~s}$. In the VI block diagram, the shape of the path, the separation between 
two consecutive steps on the path, and the number of frequencies at which parameters are evaluated $\left(N_{\text {freq }}\right)$ can be modified.

The data was collected and recorded at each position by the PNA-X (Windows 7) on a folder shared over the network with the workstation PC. The data was stored in the s2p file format. The number " 2 " in the format name indicates a two-port measurement that constitutes the magnitude $(d B)$ and phase (degrees) of $\left\{S_{11}, S_{12}, S_{21}, S_{22}\right\}$, generating eight columns of data with 8 significant digits. In general, in an $\mathrm{N}$-port measurement, the total count of complex parameters is $2 N^{2}$ when the data format is magnitude/phase. A MATLAB script was used to remove the headings of the s-parameter files and assemble them together as one single data set in "CSV" format. This file was utilized for phase stability check and image reconstruction purposes. The data collection process could be ceased by an on/off switch on the power supply, in case there was software or physical failure.

\subsection{The Bearing Ball Experiment}

A simple experimental setup was designed to assess the imaging capability of the NRIMS in detecting a scatterer embedded inside a homogeneous medium. In the case of this experiment, for simplicity, the original path of the antennas was changed (Figure 7) into a straight line passing the center of the ethanol container, when viewed from the top. The system was configured to acquire 25 data sets in 25 equally-spaced positions along the path. The s-parameter data was sampled by 64 points over the frequency span in the calibration process resulting in an overall number of $8 \times 64 \times 25=1280$ data in total.

Sunflower oil was selected as the background medium since its permittivity was relatively low, and it was comparable with that of human's breast fatty tissue as shown in Figure 8. The mean value of relative permittivity for sunflower oil and breast fat over the $1-3 \mathrm{GHz}$ span is 3.12 and 5.23 , respectively [141,142]. Though their conductivity values are quite disparate (mean value of $0.003 \mathrm{~S} / \mathrm{m}$ versus $0.1095 \mathrm{~S} / \mathrm{m}$ in that frequency range, in order), sunflower oil seemed to be a good option for this initial test where the contrast parameter (the unknown in the imaging algorithm, Section 7) was defined based on relative permittivity and not conductivity. Another container was built for the sunflower oil in which the NRIMS could be partially immersed. The end was to eliminate any air gap between the ethanol container at the bottom of the system and the oil.

The target was a steel bearing ball mounted on a small plastic base and positioned in the center of the oil container, at the bottom. The size of the ball (1 inch in diameter) was chosen to be large compared to early-stage breast tumors, because the main goal of this study was to evaluate whether the system is able to detect an object in a uniform medium. Next, the experiment setup was assembled by putting the NRIMS over the oil container, centering the two containers from the top, connecting the antennas to the PNA, and finally linking the PC to the Arduino board. After loading the VI and powering the system, two measurements were carried out, one time without the ball, as the background, and one time with the ball. The background data was required for the imaging reconstruction process which is described in Section 7. In order to examine the robustness of the imaging algorithm, the ball was placed in different positions. In each measurement, the NRIMS needed to be lifted so that the ball could be either shifted or removed. Figure 9 shows a photo of the experiment layout when the ball was placed at the center.

For a more accurate model in the imaging algorithm and the SAR analysis, the dielectric properties of absolute ethanol (200 proof) were measured using the PNA material measurement software (Keysight Material Measurement Suite 2015) and then compared with the ones reported in [125]. The curves, as plotted in Figure 10, were in good agreement and the measured data did not affect the final results significantly. 

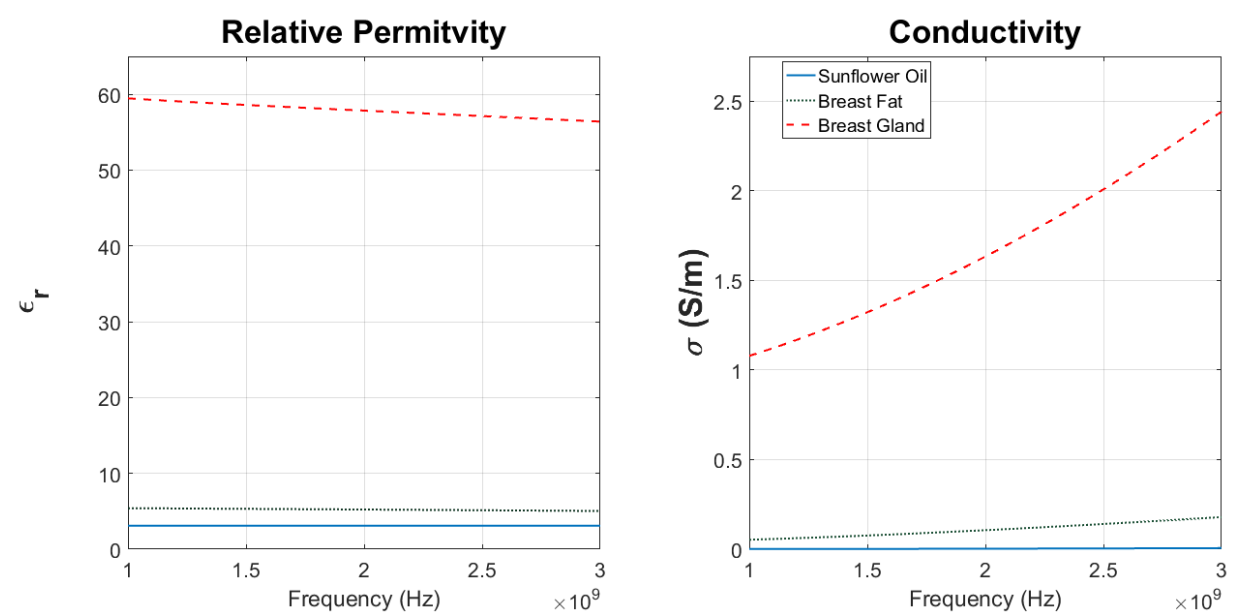

Figure 8. The relative permittivity $\epsilon_{r}$ (left) and conductivity $\sigma$ (right) of sunflower oil (solid blue) are close to the behavior of breast fat (dotted green) for the selected frequencies when compared to that of other breast tissues such as fibro-glandular tissue (dashed red) [141,142].

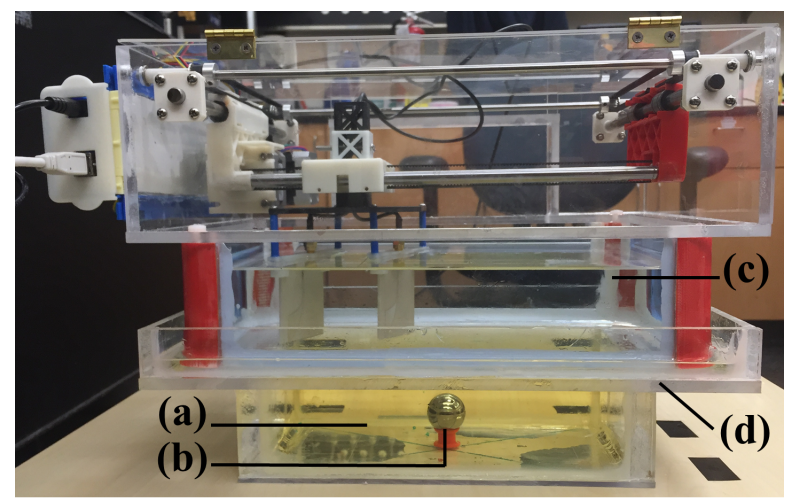

Figure 9. The bearing ball imaging experiment setup: (a) sunflower oil, (b) the bearing ball and its base, (c) the ethanol container, attached to the NRIMS and partially submerged in oil, (d) the oil container.

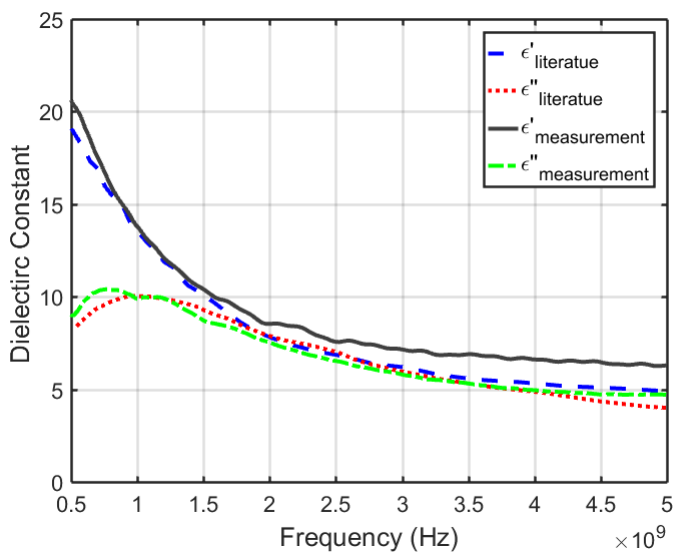

Figure 10. Dielectric properties of ethanol (200 proof) in the $0.5-5 \mathrm{GHz}$ range; measured versus what has been reported in the literature [125]. $\epsilon^{\prime}$ and $\epsilon^{\prime \prime}$ denote the real and imaginary part of the complex relative permittivity, respectively. 


\section{The SAR Simulation}

In order to ensure that the radiation from the antennas are safe for human subjects, a Specific Absorption Rate (SAR) simulation was carried out using one AVA as it radiated inside ethanol towards a breast model. SAR measures the amount of power a certain tissue absorbs when it is exposed to electromagnetic radiation [143]. The local SAR inside the tissue can be obtained as

$$
S A R_{\text {local }}(\mathbf{r}, f)=\frac{\sigma(\mathbf{r}, f)|\mathbf{E}(\mathbf{r}, f)|^{2}}{\rho(\mathbf{r})},
$$

in which $\sigma(\mathbf{r}, f)$ is the material's conductivity in $[\mathrm{S} / \mathrm{m}], \mathbf{r}$ is the position vector, $\rho(\mathbf{r})$ is the mass density of the tissue at $\mathbf{r}$ in $\left[\mathrm{Kg} / \mathrm{m}^{3}\right], f$ is the frequency in $[\mathrm{Hz}]$, and $\mathbf{E}(\mathbf{r}, f)$ is the electric field at position $\mathbf{r}$ and frequency $f$ in $[\mathrm{V} / \mathrm{m}]$. For standardization purposes, this parameter is usually averaged over a small sample volume $\Delta v(\mathbf{r})$ with a value of $V\left[\mathrm{~m}^{3}\right]$ as follows:

$$
\operatorname{SAR}_{\text {average }}(\mathbf{r}, f)=\frac{1}{V} \int_{\Delta v(\mathbf{r})} \frac{\sigma\left(\mathbf{r}^{\prime}, f\right)\left|\mathbf{E}\left(\mathbf{r}^{\prime}, f\right)\right|^{2}}{2 \rho\left(\mathbf{r}^{\prime}\right)} d \mathbf{r}^{\prime}
$$

This energy flow per second reveals itself in the form of heat or temperature gradient over time inside the tissue and if it oversteps a certain value, it could cause harm. Federal Communications Commission (FCC) in the United States has set a threshold of $1.6 \mathrm{~W} / \mathrm{kg}$ for peak SAR values in a 1-gram sample of head [143] or other body parts. In Europe, as stated by The Council of The European Union (CEU), the limit is $2 \mathrm{~W} / \mathrm{kg}$ per 10-gram samples of body parts [144]. Furthermore, IEEE Standard 1528 provides a method for calculating the peak SAR in human head when it is exposed to radio frequency radiation, which can also be applied to other body part calculations [145].

\section{Imaging Algorithm}

In order to obtain the scattered field from the total and background fields measured during the data acquisition process, the following relationship can be used [115,146]:

$$
\mathbf{E}_{s}=\mathbf{E}_{t}-\mathbf{E}_{b} \approx\left(\nabla^{2}+k_{b}^{2}\right)^{-1} k_{b}^{2} \mathbf{E}_{t} \chi_{\epsilon}
$$

where $\mathbf{E}_{t}$ is the total field vector, $\mathbf{E}_{b}$ is the background field vector, $k_{b}$ is the wave number in the background medium, and $\chi_{\epsilon}=\left(\epsilon_{t}-\epsilon_{b}\right) / \epsilon_{b}$ is the contrast between the total (unknown) and the background (known) media. All of these parameters are functions of the position vector $\mathbf{r}$ and the frequency $f$. Since $\chi_{\epsilon}$ is small in the case of breast cancer (about $10 \%$ as mentioned in Section 4), Born approximation can be applied and $\mathbf{E}_{t}$ in Equation (6) can be replaced by the known field $\mathbf{E}_{b}$. The linearized equation can then be expressed in the compressed form, $\mathbf{y}=A \mathbf{x}+\boldsymbol{\eta}$, in which $\mathbf{y} \in \mathbb{C}^{M}$ is the vector of measured scattered field, $\mathbf{x} \in \mathbb{C}^{N}$ is the contrast vector that is to be solved for, $A \in \mathbb{C}^{M \times N}$ is the sensing matrix, and finally $\eta \in \mathbb{C}^{M}$ is the measurement noise. In this case, the number of measurements is much less than the number of unknowns $(M<N)$ and thereby a regularization method is needed to acquire a unique solution for $\mathbf{x}$. Tikhonov regularization is a suitable technique for the problem at hand and gives an optimal solution to the convex optimization problem below:

$$
\begin{gathered}
\frac{1}{2}\|A \mathbf{x}-\mathbf{y}\|_{\ell_{2}}^{2}+\lambda\|\mathbf{x}\|_{\ell_{2}}^{2} \\
\text { Subject to: }\left\{\begin{array}{l}
\boldsymbol{\operatorname { R e }}\left(\operatorname{diag}\left(\epsilon_{b}\right) \mathbf{x}+\epsilon_{b}\right) \geq 1 \\
\operatorname{Im}\left(\operatorname{diag}\left(\epsilon_{b}\right) \mathbf{x}+\epsilon_{b}\right) \geq 0,
\end{array}\right.
\end{gathered}
$$

where $\lambda$ is the regularization parameter, and the optimization conditions are to make the contrast parameter physically realizable ( $\epsilon_{r} \geq 1, \sigma \geq 0$ ) [147]. In place of Equation (7), other regularization 
methods such as $\frac{1}{2}\|A \mathbf{x}-\mathbf{y}\|_{\ell_{2}}^{2}+\lambda\|\mathbf{x}\|_{\ell_{1}}$ can be utilized with the same optimization conditions, as described in [115].

\section{Results}

\subsection{SAR Analysis}

ANSYS HFSS was employed to study the SAR of the heat induced by an AVA inside a breast model placed under the antenna. The model constituted the data of fat distribution inside a real, healthy breast whose image was obtained by the DBT at the MGH. Figure 11 shows the fat distribution in the breast model from different views. The maximum value of 1 in the color bar shows $100 \%$ fat composition.

The original model of the breast contained a large data matrix, so instead of importing the whole data set into HFSS, the fat ratio values were averaged in cubes of 6-mm sides and imported as a new object in the software, thus reducing the computational load. Note that the discretization for the full-wave simulation was still kept at one tenth of a wavelength inside each cube. Then, the complex dielectric properties of the breast were approximated with a Cole-to-Cole model. The effect of the compression paddle and ethanol container were also taken into account by setting up a simplified geometry of the real system as shown in Figure 12. In the real system, the input power by the PNA was $0 \mathrm{dBm}(1 \mathrm{~mW})$, and thus the simulations were configured accordingly.

HFSS automatically implements the IEEE Standard P1528.4 to compute the spatial-average of SAR inside 1- and 10-gram samples [148]. The results for both sample models in two different frequencies are displayed in Figure 13. It is apparent that the peak SAR in all the cases is certainly below the FCC and CEU standards, by at least three orders of magnitude, suggesting that the radiation from the antenna set is safe for human use, even if sixteen antennas were used instead of one.
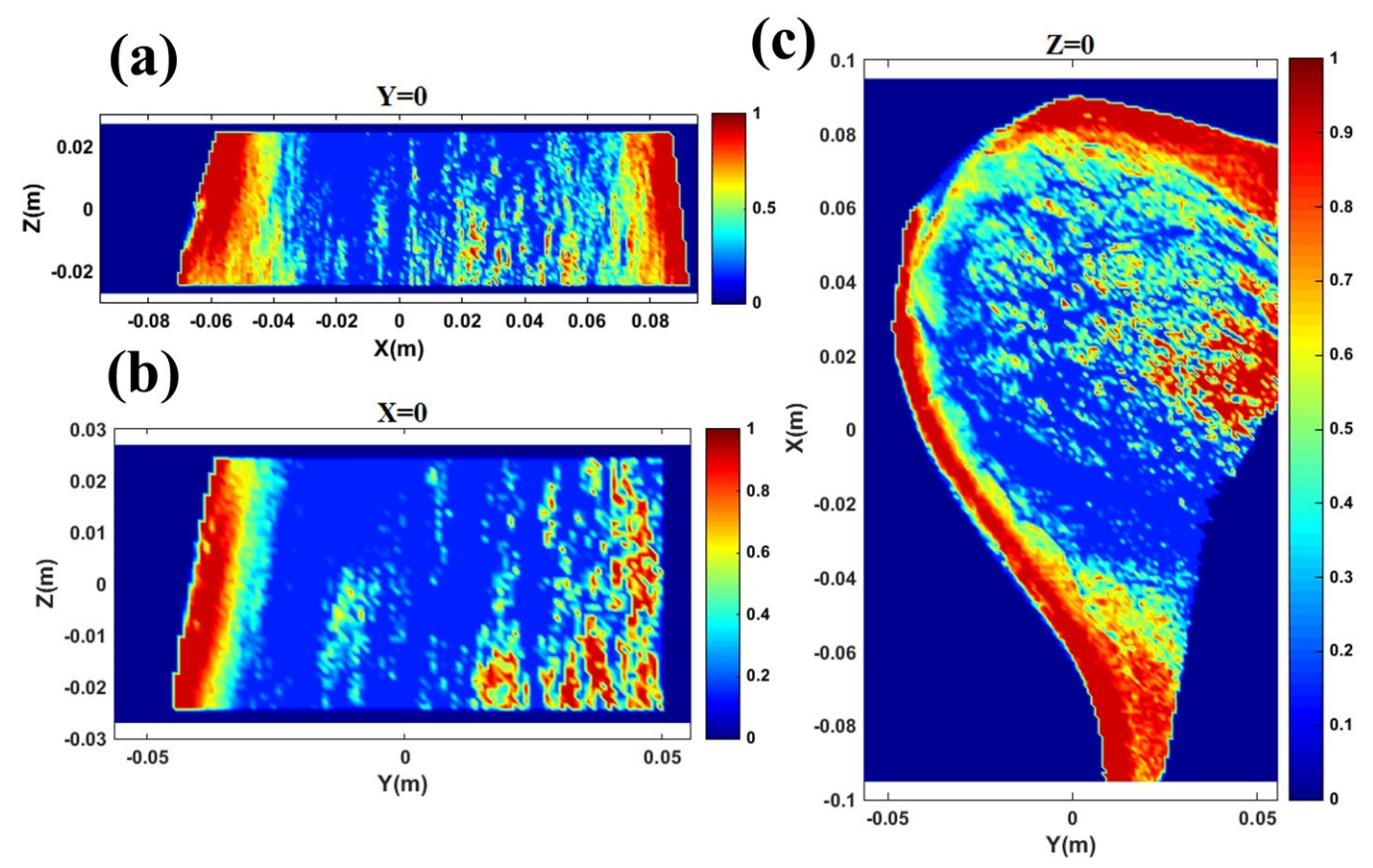

Figure 11. Fat distribution (dark red corresponds to $100 \%$ fat) in a healthy breast from a DBT image as seen from (a) front, (b) side, (c) and above. The margins of the breast are composed of $80-100 \%$ fat. 


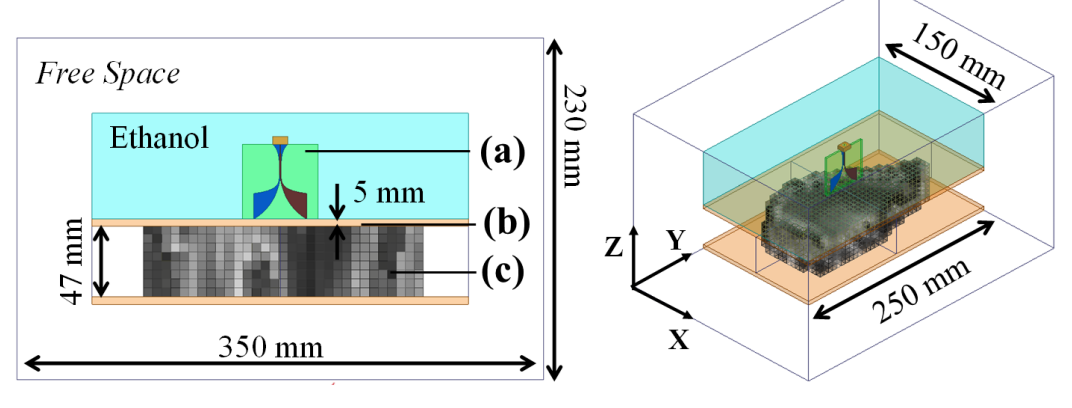

Figure 12. Simulation geometry in HFSS: (a) AVA, (b) acrylic sheet, (c) compressed breast model discretized into tiny cubes of $6 \mathrm{~mm}$ sides. On the right, an isometric view of the configuration is displayed.

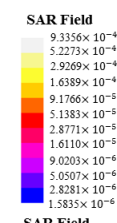

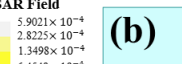

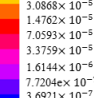

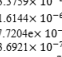

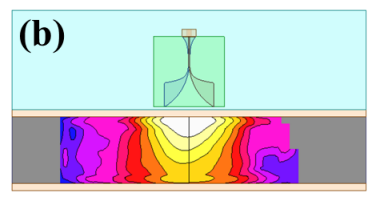

(a)
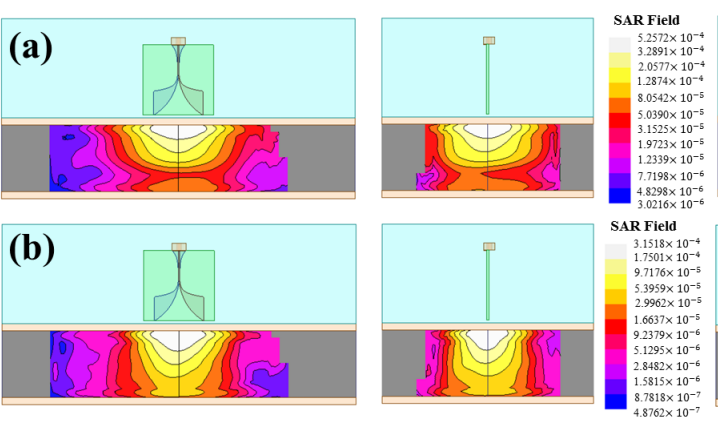

(c)

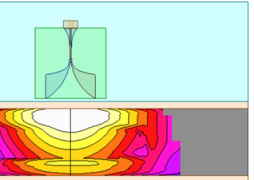

(d)

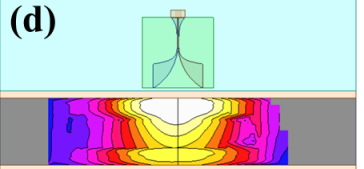

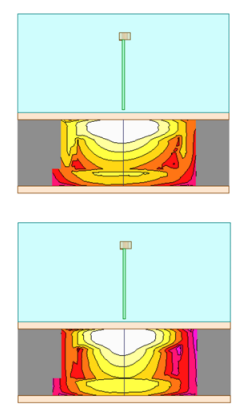

Figure 13. SAR analysis results with $1 \mathrm{~g}$ and $10 \mathrm{~g}$ samples at $1 \mathrm{GHz}$ and $2.5 \mathrm{GHz}$ : (a) $1 \mathrm{~g}$ at $1 \mathrm{GHz}$, (b) $1 \mathrm{~g}$ at $2.5 \mathrm{GHz}$, (c) $10 \mathrm{~g}$ at $1 \mathrm{GHz}$, (d) $10 \mathrm{~g}$ at $2.5 \mathrm{GHz}$. The peak SAR is much smaller than the US (EU) standard, $1.6 \mathrm{~W} / \mathrm{Kg}(2 \mathrm{~W} / \mathrm{Kg})$, in all settings.

\subsection{Bearing Ball Imaging}

Using the approach described in Section 7, the image of the ball was reconstructed in the XZ plane at two different positions: first at $1 \mathrm{~cm}$ off-center and second at $5 \mathrm{~cm}$ off-center, in the $X$ direction. To assess the obtained results, the same geometry was also configured in MATLAB for both cases, and the problem was solved for the unknown variable $\chi_{\epsilon}$ using the Finite Differences in the Frequency Domain (FDFD) method. Figure 14 illustrates the results both from the simulations and the measurements. The measurements are carried out by both regular $(a, d)$ and phase-stable $(b, e)$ cables.

As can be observed, the retrieved images from the measurements show similar patterns to those obtained from simulations. They all present a maximum intensity signature at the surface of metallic ball, not inside of it where the electromagnetic fields are zero due to its high conductivity. Moreover, there are some artifacts in the images obtained from measured data, which are located at the interface between the mechatronic system and the sunflower oil. These artifacts suggest that there is a slight inaccuracy in the numerically computed Green's Functions for the background media. Enhancing the accuracy of these functions, by measuring the radiated patterns, might improve the performance of the NRIMS even more.

The resolution of the images can be improved using a wider bandwidth, more data, and finer regularization. Further, case (b), with phase-stable cables, seems closer to the simulation than (a), which is done by regular cables. Yet, in case (e), the circular shape that appears in all other images has been lost. In other words, the phase-stable cables have not noticeably enhanced or degraded the quality or accuracy of the reconstructed images in comparison with the regular cables, in general. More scrutinization is needed to evaluate the effect of cable type on the final image quality. 

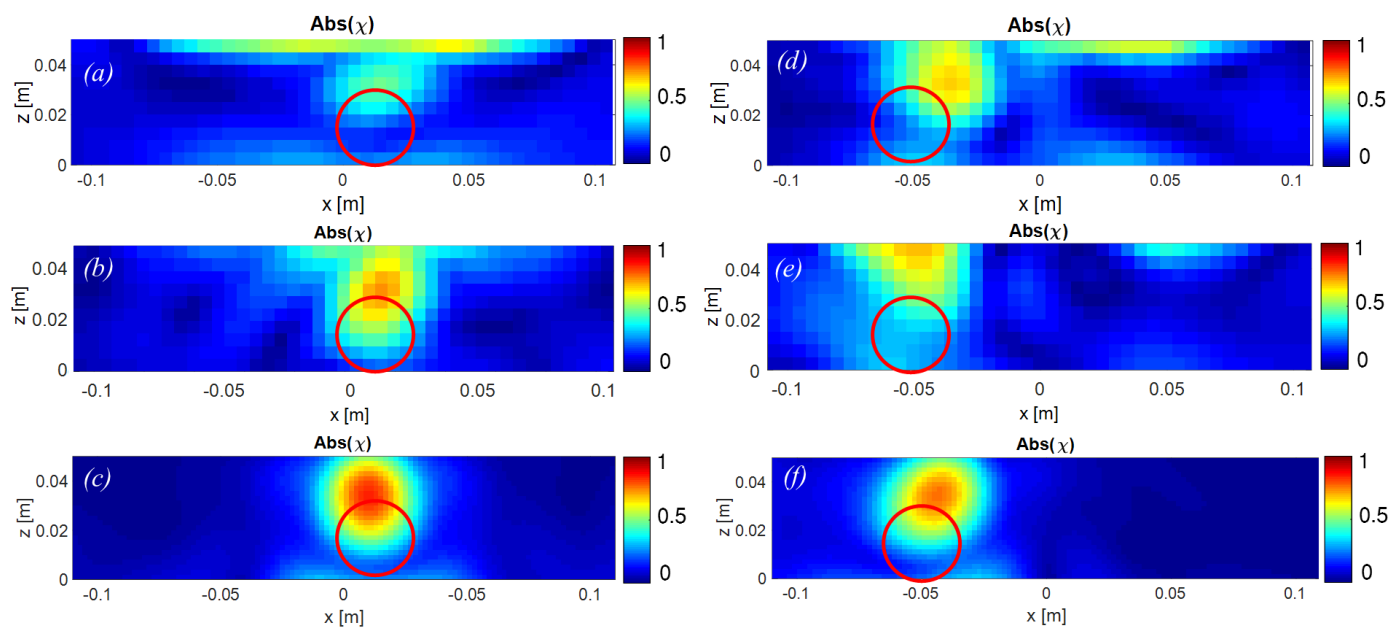

Figure 14. Reconstructed images for the contrast $\chi_{\epsilon}$ using (a) measurement; regular cable, ball located at $x=0.01 \mathrm{~m}$ (b) measurement; phase-stable cable, ball located at $x=0.01 \mathrm{~m}$ (c) simulation, ball located at $x=0.01 \mathrm{~m},(\mathbf{d})$ measurement; regular cable, ball located at $x=-0.05 \mathrm{~m},(\mathbf{e})$ measurement; phase-stable cable, ball located at $x=0.01 \mathrm{~m}$ (f) simulation, ball located at $x=-0.05 \mathrm{~m}$. The values of the contrast are normalized with respect to the maximum value in each case.

\section{Discussion}

Using a simplified experimental layout, the developed NRI mechatronic system was assessed in terms of its capability to image a target. The experiment was designed only for proof-of-concept and accordingly it made the following simplifications: (i) the background medium (sunflower oil) was selected to be homogeneous, and (ii) the target was selected to be relatively large and a strong scatterer (a metallic ball, 1 inch in diameter). Though this experiment differs importantly from the case of the breast that has heterogeneous composition whose early-stage tumors are in order of millimeters, it shows the ability of the system to collect repeatable data from a medium and to translate it into dielectric maps or microwave images. In future, more realistic breast phantoms need to be imaged to show the full capability of the system. Also, the idea of using X-ray images as prior information for NRI, whose simulations results are presented in [115,147], can be materialized by collecting data from both the NRIMS and the DBT at the MGH. As shown by Jiang et al. in [103], in the case of a bimodal ultrasound-microwave system where ultrasound prior information was used for the NRI, it is predicted that using the prior information from the DBT could enhance the microwave image resolution significantly. In their case, the resolution was refined from $10 \mathrm{~mm}$ to $1.2 \mathrm{~mm}$ [103].

The novelty of the system designed, fabricated, and presented in this study lies in the fact that the NRIMS is compact, portable, and compatible with the DBT machine, enabling a co-registered scan of the breast. In other words, this system could be utilized as an add-on modality and scan the compressed breast within the same 3D mammography session, by being placed inside the compression paddle of the DBT. It should be noted that modifying the dimensions of the system's frame allows it to be used in other state-of-the-art breast scanning machines such as automated breast ultrasound (ABUS) [149], molecular breast imaging (MBI) [150], and MicroDose SI [151]. In this regard, the NRIMS is unique from other microwave imaging systems, which require a separate scan session if they are to be used as an auxiliary modality $[71,104,106,152]$. Moreover, the NRIMS operates in the same setting of a mammography session with a compressed breast, eliminating the problem of tissue motion [69]. The problem of metallic parts interfering with magnetic fields in the MRI machine, which was reported by Golnabi [73] in the case of microwave-magnetic-resonance dual imaging, also does not arise in the NRIMS, due to using X-ray as the second modality and the ease in removing the NRIMS from the compression paddle. 


\section{Conclusions}

This paper presents a comprehensive review of the literature associated with some of the major challenges existing in conventional breast imaging systems, particularly 2D mammography. This review acknowledged the need to improve current imaging systems, so that the breast cancer detection can be done at earlier stages of the disease while reducing false positive and negative rates. To the best of our knowledge, this paper presents the first NRI experimental system that can be used in a co-registered fashion with the DBT machine at the MGH. This system is equipped with a pair of UWB AVAs that are capable of radiating in a medium of high dielectric constant and can mechanically scan a medium using a LabView-Arduino virtual interface, developed in-house. The basic performance of the system was tested in order to produce the first set of images while keeping the radiated power levels safe for human exposure. The results show that, firstly, the Specific Absorption Rate (SAR) of the heat induced by the microwave radiation from the antennas in the tissue is indeed below the limit set by the FCC in the USA and the CEU in Europe; and, secondly, the system is capable of detecting a strong scattering object (a bearing ball) inside an oil container. The experimental images are in good agreement with those that were computationally generated by using an FDFD software. Notwithstanding that the preliminary results of this first prototype are recognizable, it is important to acknowledge that the experiment setup is rather simple in this work, since a comparatively large target was used. Therefore, the on-going research is aimed at examining how the NRIMS performs in detecting smaller inclusions in various and more complex geometries and background media of different material properties. Additionally, the use of the DBT images for prior information in the microwave reconstruction is currently under investigation, so that the fully hybrid, bimodal system could be used in its full potential in the clinical setting.

Acknowledgments: This work is partially funded by The Massachusetts Technology Transfer Center (MTTC), the National Science Foundation award number 1347454, and Martinez's start-up grant at Northeastern University. We would like to thank Richard H. Moore, Daniel B. Kopans M.D., and Jayne A. Cromier at the MGH for their intellectual consult and support in the project.

Author Contributions: Ashkan Ghanbarzadeh Dagheyan built the mechatronic system, carried out the experiments, and wrote the main manuscript and the literature review; Ali Molaei designed the AVAs, ran all the simulations related to the AVAs (including the field and the SAR computations) and the generation of the sensing matrix, and helped with the experiments; Richard Obermeier did the imaging of the bearing ball; Andrew Westwood contributed to setting up the PNA experiments, Aida Martinez assisted in the medical review and potential transition of the system into the clinical setting; and Jose Martinez Lorenzo coordinated the whole effort as the lead Principal Investigator of this project.

Conflicts of Interest: The authors declare no conflict of interest. The funding sponsors had no role in the design of the study; in the collection, analyses, or interpretation of data; in the writing of the manuscript, and in the decision to publish the results.

\section{Abbreviations}

The following abbreviations are used in this manuscript (in the order of appearance):

$\begin{array}{ll}\text { MGH } & \text { Massachuestts General Hospital } \\ \text { DBT } & \text { Digital Breat Tomosynthesis } \\ \text { NRI } & \text { Near-field Radar Imaging } \\ \text { SAR } & \text { Specific Absoprtion Rate } \\ \text { FP } & \text { False-positive } \\ \text { FN } & \text { False-negative } \\ \text { BSE } & \text { Breast self-examination } \\ \text { FFDM } & \text { Full-field Digital Mammography } \\ \text { UWB } & \text { Ultra-wideband } \\ \text { NRIMS } & \text { Near-field Radar Imaging Mechatronic System } \\ \text { AVA } & \text { Antipodal Vivaldi Antenna } \\ \text { PNA } & \text { Programmable Network Analyzer } \\ \text { FCC } & \text { Federal Communications Commission } \\ \text { CEU } & \text { The Council of European Union }\end{array}$




\section{References}

1. U.S. Cancer Statistics Working Group. United States Cancer Statistics: 1999-2013 Incidence and Mortality Web-based Report.Atlanta: U.S. Department of Health and Human Services, Centers for Disease Control and Prevention and National Cancer Institute. 2016. Available online: https:/ /nccd.cdc.gov/uscs/toptencancers. aspx (accessed on 17 May 2017).

2. American Cancer Society. Breast Cancer Facts E Figures 2013-2014; American Cancer Society, Inc.: Atlanta, GA, USA, 2013.

3. Howlader, N.; Noone, A.; Krapcho, M.; Garshell, J.; Neyman, N.; Altekruse, S.; Kosary, C.; Yu, M.; Ruhl, J.; Tatalovich, Z.; et al. SEER Cancer Statistics Review, 1975-2010; National Cancer Institute: Bethesda, MD, USA, 2013.

4. Hubbard, R.A.; Kerlikowske, K.; Flowers, C.I.; Yankaskas, B.C.; Zhu, W.; Miglioretti, D.L. Cumulative probability of false-positive recall or biopsy recommendation after 10 years of screening mammography: A cohort study. Ann. Intern. Med. 2011, 155, 481-492.

5. Tagliafico, A.; Mariscotti, G.; Durando, M.; Stevanin, C.; Tagliafico, G.; Martino, L.; Bignotti, B.; Calabrese, M.; Houssami, N. Characterisation of microcalcification clusters on 2D digital mammography (FFDM) and digital breast tomosynthesis (DBT): Does DBT underestimate microcalcification clusters? Results of a multicentre study. Eur. Radiol. 2015, 25, 9-14.

6. Karahaliou, A.; Skiadopoulos, S.; Boniatis, I.; Sakellaropoulos, P.; Likaki, E.; Panayiotakis, G.; Costaridou, L. Texture analysis of tissue surrounding microcalcifications on mammograms for breast cancer diagnosis. Br. J. Radiol. 2014, 80, 648-656.

7. Oliveira, B.; Glavin, M.; Jones, E.; O’Halloran, M.; Conceição, R. Avoiding unnecessary breast biopsies: Clinically-informed 3D breast tumour models for microwave imaging applications. In Proceedings of the 2014 IEEE Antennas and Propagation Society International Symposium (APSURSI), Memphis, TN, USA, 6-11 July 2014.

8. Anand, P.; Kunnumakara, A.B.; Sundaram, C.; Harikumar, K.B.; Tharakan, S.T.; Lai, O.S.; Sung, B.; Aggarwal, B.B. Cancer is a preventable disease that requires major lifestyle changes. Pharm. Res. 2008, 25, 2097-2116.

9. Willett, W.C.; Koplan, J.P.; Nugent, R.; Dusenbury, C.; Puska, P.; Gaziano, T.A. Prevention of chronic disease by means of diet and lifestyle changes. In Disease Control Priorities in Developing Countries; The World Bank Group: Washington, DC, USA, 2006.

10. World Health Organization. Cancer. Available online: http://www.who.int/mediacentre/factsheets/fs297/ en/ (accessed on 5 May 2017).

11. American Cancer Society. Breast Cancer Prevention and Early Detection; American Cancer Society, Inc.: Atlanta, GA, USA, 2013.

12. Berry, D.A.; Cronin, K.A.; Plevritis, S.K.; Fryback, D.G.; Clarke, L.; Zelen, M.; Mandelblatt, J.S.; Yakovlev, A.Y.; Habbema, J.D.F.; Feuer, E.J. Effect of screening and adjuvant therapy on mortality from breast cancer. N. Engl. J. Med. 2005, 353, 1784-1792.

13. Blanks, R.; Moss, S.; McGahan, C.; Quinn, M.; Babb, P. Effect of NHS breast screening programme on mortality from breast cancer in England and Wales, 1990-8: Comparison of observed with predicted mortality. BMJ 2000, 321, 665-669.

14. Otto, S.J.; Fracheboud, J.; Looman, C.W.; Broeders, M.J.; Boer, R.; Hendriks, J.H.; Verbeek, A.L.; de Koning, H.J.; National Evaluation Team for Breast Cancer Screening. Initiation of population-based mammography screening in Dutch municipalities and effect on breast-cancer mortality: A systematic review. Lancet 2003, 361, 1411-1417.

15. Lenner, P.; Jonsson, H. Excess mortality from breast cancer in relation to mammography screening in northern Sweden. J. Med. Screen. 1997, 4, 6-9.

16. Jonsson, H.; Nyström, L.; Törnberg, S.; Lenner, P. Service screening with mammography of women aged 50-69 years in Sweden: Effects on mortality from breast cancer. J. Med. Screen. 2001, 8, 152-160.

17. Jonsson, H.; Bordás, P.; Wallin, H.; Nyström, L.; Lenner, P. Service screening with mammography in Northern Sweden: Effects on breast cancer mortality-An update. J. Med. Screen. 2007, 14, 87-93.

18. Olsen, A.H.; Njor, S.H.; Vejborg, I.; Schwartz, W.; Dalgaard, P.; Jensen, M.B.; Tange, U.B.; Blichert-Toft, M.; Rank, F.; Mouridsen, H.; et al. Breast cancer mortality in Copenhagen after introduction of mammography screening: Cohort study. BMJ 2005, 330, 220. 
19. Lee, C.H.; Dershaw, D.D.; Kopans, D.; Evans, P.; Monsees, B.; Monticciolo, D.; Brenner, R.J.; Bassett, L.; Berg, W.; Feig, S.; et al. Breast cancer screening with imaging: Recommendations from the Society of Breast Imaging and the ACR on the use of mammography, breast MRI, breast ultrasound, and other technologies for the detection of clinically occult breast cancer. J. Am. Coll. Radiol. 2010, 7, 18-27.

20. World Health Organization. WHO Position Paper on Mammography Screening; World Health Organization: Geneva, Switzerland, 2014.

21. Kalager, M.; Zelen, M.; Langmark, F.; Adami, H.O. Effect of screening mammography on breast-cancer mortality in Norway. N. Engl. J. Med. 2010, 363, 1203-1210.

22. Bleyer, A.; Welch, H.G. Effect of three decades of screening mammography on breast-cancer incidence. N. Engl. J. Med. 2012, 367, 1998-2005.

23. Miller, A.B.; Wall, C.; Baines, C.J.; Sun, P.; To, T.; Narod, S.A. Twenty five year follow-up for breast cancer incidence and mortality of the Canadian National Breast Screening Study: Randomised screening trial. BMJ 2014, 348, g366.

24. Gøtzsche, P.C. Mammography screening is harmful and should be abandoned. J. R. Soc. Med. 2015, 108, 341-345.

25. Kopans, D.B. Digital breast tomosynthesis from concept to clinical care. Am. J. Roentgenol. 2014, 202, $299-308$.

26. Christiansen, C.L.; Wang, F.; Barton, M.B.; Kreuter, W.; Elmore, J.G.; Gelfand, A.E.; Fletcher, S.W. Predicting the cumulative risk of false-positive mammograms. J. Natl. Cancer Inst. 2000, 92, 1657-1666.

27. Castells, X.; Molins, E.; Macià, F. Cumulative false positive recall rate and association with participant related factors in a population based breast cancer screening programme. J. Epidemiol. Community Health 2006, 60, 316-321.

28. Warren Burhenne, L.J.; Wood, S.A.; D’Orsi, C.J.; Feig, S.A.; Kopans, D.B.; O'Shaughnessy, K.F.; Sickles, E.A.; Tabar, L.; Vyborny, C.J.; Castellino, R.A. Potential contribution of computer-aided detection to the sensitivity of screening mammography. Radiology 2000, 215, 554-562.

29. Kerlikowske, K.; Grady, D.; Barclay, J.; Sickles, E.A.; Ernster, V. Effect of age, breast density, and family history on the sensitivity of first screening mammography. JAMA 1996, 276, 33-38.

30. Gram, I.; Lund, E.; Slenker, S. Quality of life following a false positive mammogram. Br. J. Cancer 1990, 62, 1018-1022.

31. Welch, H.G.; Passow, H.J. Quantifying the benefits and harms of screening mammography. JAMA Intern. Med. 2014, 174, 448-454.

32. Brewer, N.T.; Salz, T.; Lillie, S.E. Systematic review: The long-term effects of false-positive mammograms. Ann. Intern. Med. 2007, 146, 502-510.

33. Aro, A.R.; Absetz, S.P.; van Elderen, T.M.; van der Ploeg, E.; van der Kamp, L.T. False-positive findings in mammography screening induces short-term distress-Breast cancer-specific concern prevails longer. Eur. J. Cancer 2000, 36, 1089-1097.

34. Lampic, C.; Thurfjell, E.; Sjödén, P.O. The influence of a false-positive mammogram on a woman's subsequent behaviour for detecting breast cancer. Eur. J. Cancer 2003, 39, 1730-1737.

35. Burman, M.L.; Taplin, S.H.; Herta, D.F.; Elmore, J.G. Effect of false-positive mammograms on interval breast cancer screening in a health maintenance organization. Ann. Intern. Med. 1999, 131, 1-6.

36. Tosteson, A.N.; Fryback, D.G.; Hammond, C.S.; Hanna, L.G.; Grove, M.R.; Brown, M.; Wang, Q.; Lindfors, K.; Pisano, E.D. Consequences of false-positive screening mammograms. JAMA Intern. Med. 2014, 174, 954-961.

37. McCann, J.; Stockton, D.; Godward, S. Impact of false-positive mammography on subsequent screening attendance and risk of cancer. Breast Cancer Res. 2002, 4, R11.

38. Henderson, L.M.; Hubbard, R.A.; Sprague, B.L.; Zhu, W.; Kerlikowske, K. Increased risk of developing breast cancer after a false-positive screening mammogram. Cancer Epidemiol. Prev. Biomark. 2015, 24, 1882-1889.

39. Castells, X.; Roman, M.; Romero, A.; Blanch, J.; Zubizarreta, R.; Ascunce, N.; Salas, D.; Burón, A.; Sala, M.; Cumulative False Positive Risk Group. Breast cancer detection risk in screening mammography after a false-positive result. Cancer Epidemiol. 2013, 37, 85-90.

40. Von Euler-Chelpin, M.; Risør, L.M.; Thorsted, B.L.; Vejborg, I. Risk of breast cancer after false-positive test results in screening mammography. J. Natl. Cancer Inst. 2012, 104, 682-689.

41. Wong, S.Y.; Reiter, J.F. Wounding mobilizes hair follicle stem cells to form tumors. Proc. Natl. Acad. Sci. USA 2011, 108, 4093-4098.

42. Rigby, J.; Morris, J.; Lavelle, J.; Stewart, M.; Gatrell, A. Can physical trauma cause breast cancer? Eur. J. Cancer Prev. 2002, 11, 307-311. 
43. Hansen, N.M.; Ye, X.; Grube, B.J.; Giuliano, A.E. Manipulation of the primary breast tumor and the incidence of sentinel node metastases from invasive breast cancer. Arch. Surg. 2004, 139, 634-640.

44. Wu, M.; Pastor-Pareja, J.C.; Xu, T. Interaction between RasV12 and scribbled clones induces tumour growth and invasion. Nature 2010, 463, 545-548.

45. Pijpe, A.; Andrieu, N.; Easton, D.F.; Kesminiene, A.; Cardis, E.; Noguès, C.; Gauthier-Villars, M.; Lasset, C.; Fricker, J.P.; Peock, S.; et al. Exposure to diagnostic radiation and risk of breast cancer among carriers of BRCA1/2 mutations: retrospective cohort study (GENE-RAD-RISK). BMJ 2012, 345, e5660.

46. Salz, T.; Richman, A.R.; Brewer, N.T. Meta-analyses of the effect of false-positive mammograms on generic and specific psychosocial outcomes. Psycho-Oncology 2010, 19, 1026-1034.

47. Lillberg, K.; Verkasalo, P.K.; Kaprio, J.; Teppo, L.; Helenius, H.; Koskenvuo, M. Stressful life events and risk of breast cancer in 10,808 women: A cohort study. Am. J. Epidemiol. 2003, 157, 415-423.

48. Chida, Y.; Hamer, M.; Wardle, J.; Steptoe, A. Do stress-related psychosocial factors contribute to cancer incidence and survival? Nat. Clin. Pract. Oncol. 2008, 5, 466-475.

49. Herbert, T.B.; Cohen, S. Stress and immunity in humans: A meta-analytic review. Psychosom. Med. 1993, 55, 364-379.

50. Dhabhar, F.S. Effects of stress on immune function: The good, the bad, and the beautiful. Immunol. Res. 2014, 58, 193-210.

51. Reiche, E.M.V.; Nunes, S.O.V.; Morimoto, H.K. Stress, depression, the immune system, and cancer. Lancet Oncol. 2004, 5, 617-625.

52. Segerstrom, S.C.; Miller, G.E. Psychological stress and the human immune system: A meta-analytic study of 30 years of inquiry. Psychol. Bull. 2004, 130, 601.

53. Currency Converter. Available online: https:/ / www.oanda.com/currency/converter/ (accessed on 22 April 2016).

54. Lidbrink, E.; Elfving, J.; Frisell, J.; Jonsson, E. Neglected aspects of false positive findings of mammography in breast cancer screening: Analysis of false positive cases from the Stockholm trial. BMJ 1996, 312, $273-276$.

55. Cole, E.B.; Pisano, E.D.; Kistner, E.O.; Muller, K.E.; Brown, M.E.; Feig, S.A.; Jong, R.A.; Maidment, A.D.; Staiger, M.J.; Kuzmiak, C.M.; et al. Diagnostic accuracy of digital mammography in patients with dense breasts who underwent problem-solving mammography: Effects of image processing and lesion type. Radiology 2003, 226, 153-160.

56. Baldwin, P. Digital breast tomosynthesis. Radiol. Technol. 2009, 81, 57M-74M.

57. Sechopoulos, I. A review of breast tomosynthesis. Part II. Image reconstruction, processing and analysis, and advanced applications. Med. Phys. 2013, 40, doi:10.1118/1.4770281.

58. Pisano, E.D.; Gatsonis, C.; Hendrick, E.; Yaffe, M.; Baum, J.K.; Acharyya, S.; Conant, E.F.; Fajardo, L.L.; Bassett, L.; D'Orsi, C.; et al. Diagnostic performance of digital versus film mammography for breast-cancer screening. N. Engl. J. Med. 2005, 353, 1773-1783.

59. Park, J.M.; Franken, E.A., Jr.; Garg, M.; Fajardo, L.L.; Niklason, L.T. Breast tomosynthesis: Present considerations and future applications 1. Radiographics 2007, 27, S231-S240.

60. Teertstra, H.J.; Loo, C.E.; Van den Bosch, M.A.; Van Tinteren, H.; Rutgers, E.J.; Muller, S.H.; Gilhuijs, K.G. Breast tomosynthesis in clinical practice: Initial results. Eur. Radiol. 2010, 20, 16-24.

61. Bernardi, D.; Ciatto, S.; Pellegrini, M.; Anesi, V.; Burlon, S.; Cauli, E.; Depaoli, M.; Larentis, L.; Malesani, V.; Targa, L.; et al. Application of breast tomosynthesis in screening: Incremental effect on mammography acquisition and reading time. Br. J. Radiol. 2014, 85, e1174-e1178

62. Gur, D.; Abrams, G.S.; Chough, D.M.; Ganott, M.A.; Hakim, C.M.; Perrin, R.L.; Rathfon, G.Y.; Sumkin, J.H.; Zuley, M.L.; Bandos, A.I. Digital breast tomosynthesis: Observer performance study. Am. J. Roentgenol. 2009, 193, 586-591.

63. Houssami, N.; Macaskill, P.; Bernardi, D.; Caumo, F.; Pellegrini, M.; Brunelli, S.; Tuttobene, P.; Bricolo, P.; Fantò, C.; Valentini, M.; et al. Breast screening using 2D-mammography or integrating digital breast tomosynthesis (3D-mammography) for single-reading or double-reading-Evidence to guide future screening strategies. Eur. J. Cancer 2014, 50, 1799-1807.

64. Bernardi, D.; Caumo, F.; Macaskill, P.; Ciatto, S.; Pellegrini, M.; Brunelli, S.; Tuttobene, P.; Bricolo, P.; Fantò, C.; Valentini, M.; et al. Effect of integrating 3D-mammography (digital breast tomosynthesis) with 2D-mammography on radiologists' true-positive and false-positive detection in a population breast screening trial. Eur. J. Cancer 2014, 50, 1232-1238. 
65. Gilbert, F.J.; Tucker, L.; Gillan, M.G.; Willsher, P.; Cooke, J.; Duncan, K.A.; Michell, M.J.; Dobson, H.M.; Lim, Y.Y.; Suaris, T.; et al. Accuracy of digital breast tomosynthesis for depicting breast cancer subgroups in a UK retrospective reading study (TOMMY trial). Radiology 2015, 277, 697-706.

66. Rappaport, C.; Tivnan, M.; Kaeli, E.; Obermeier, R.; Moore, R.; Kopans, D.; Martinez-Lorenzo, J. Fusing Microwave Radar Imaging with Digital Breast Tomosynthesis for High Contrast, High Resolution Breast Cancer Detection. In Proceedings of the RSNA 100th Scientific Assembly and Annual Meeting, Chicago, IL, USA, 30 November-5 December 2014.

67. Martellosio, A.; Pasian, M.; Bozzi, M.; Perregrini, L.; Mazzanti, A.; Svelto, F.; Summers, P.E.; Renne, G.; Preda, L.; Bellomi, M. Dielectric properties characterization from 0.5 to $50 \mathrm{GHz}$ of breast cancer tissues. IEEE Trans. Microw. Theory Tech. 2017, 65, 998-1011.

68. Di Meo, S.; Espín-López, P.F.; Martellosio, A.; Pasian, M.; Matrone, G.; Bozzi, M.; Magenes, G.; Mazzanti, A.; Perregrini, L.; Svelto, F.; et al. On the Feasibility of Breast Cancer Imaging Systems at Millimeter-Waves Frequencies. IEEE Trans. Microw. Theory Tech. 2017, 65, 1795-1806.

69. Nikolova, N.K. Microwave imaging for breast cancer. IEEE Microw. Mag. 2011, 12, 78-94.

70. Lazebnik, M.; Popovic, D.; McCartney, L.; Watkins, C.B.; Lindstrom, M.J.; Harter, J.; Sewall, S.; Ogilvie, T.; Magliocco, A.; Breslin, T.M.; et al. A large-scale study of the ultrawideband microwave dielectric properties of normal, benign and malignant breast tissues obtained from cancer surgeries. Phys. Med. Biol. 2007, 52, 6093.

71. Meaney, P.M.; Fanning, M.W.; Li, D.; Poplack, S.P.; Paulsen, K.D. A clinical prototype for active microwave imaging of the breast. IEEE Trans. Microw. Theory Tech. 2000, 48, 1841-1853.

72. Halter, R.J.; Zhou, T.; Meaney, P.M.; Hartov, A.; Barth, R.J., Jr.; Rosenkranz, K.M.; Wells, W.A.; Kogel, C.A.; Borsic, A.; Rizzo, E.J.; et al. The correlation of in vivo and ex vivo tissue dielectric properties to validate electromagnetic breast imaging: Initial clinical experience. Physiol. Meas. 2009, 30, S121.

73. Golnabi, A.H. Computational Aspect of Tomographic Microwave Imaging for Biomedical Applications; Dartmouth College: Hanover, NH, USA, 2012.

74. Franchois, A.; Pichot, C. Microwave imaging-complex permittivity reconstruction with a Levenberg-Marquardt method. IEEE Trans. Antennas Propag. 1997, 45, 203-215.

75. Joachimowicz, N.; Pichot, C.; Hugonin, J.P. Inverse scattering: An iterative numerical method for electromagnetic imaging. IEEE Trans. Antennas Propag. 1991, 39, 1742-1753.

76. Rubæk, T.; Meaney, P.M.; Meincke, P.; Paulsen, K.D. Nonlinear microwave imaging for breast-cancer screening using Gauss-Newton's method and the CGLS inversion algorithm. IEEE Trans. Antennas Propag. 2007, 55, 2320-2331.

77. Meaney, P.M.; Paulsen, K.D.; Ryan, T.P. Two-dimensional hybrid element image reconstruction for TM illumination. IEEE Trans. Antennas Propag. 1995, 43, 239-247.

78. Li, D.; Meaney, P.M.; Paulsen, K.D. Conformal microwave imaging for breast cancer detection. IEEE Trans. Microw. Theory Tech. 2003, 51, 1179-1186.

79. Winters, D.W.; Shea, J.D.; Kosmas, P.; Van Veen, B.D.; Hagness, S.C. Three-dimensional microwave breast imaging: Dispersive dielectric properties estimation using patient-specific basis functions. IEEE Trans. Med. Imaging 2009, 28, 969-981.

80. Gilmore, C.; Abubakar, A.; Hu, W.; Habashy, T.M.; van den Berg, P.M. Microwave biomedical data inversion using the finite-difference contrast source inversion method. IEEE Trans. Antennas Propag. 2009, 57, 1528-1538.

81. Dong, Q.; Rappaport, C.M. Microwave subsurface imaging using direct finite-difference frequencydomain-based inversion. IEEE Trans. Geosci. Remote Sens. 2009, 47, 3664-3670.

82. Firoozabadi, R.; Miller, E.L. Finite element modeling of electromagnetic scattering for microwave breast cancer detection. Skin 2010, 15, 74.

83. Meaney, P.M.; Fanning, M.W.; Raynolds, T.; Fox, C.J.; Fang, Q.; Kogel, C.A.; Poplack, S.P.; Paulsen, K.D. Initial clinical experience with microwave breast imaging in women with normal mammography. Acad. Radiol. 2007, 14, 207-218.

84. Li, Q.; Xiao, X.; Wang, L.; Song, H.; Kono, H.; Liu, P.; Lu, H.; Kikkawa, T. Direct Extraction of Tumor Response Based on Ensemble Empirical Mode Decomposition for Image Reconstruction of Early Breast Cancer Detection by UWB. IEEE Trans. Biomed. Circuits Syst. 2015, 9, 710-724.

85. Smith, D.; Leach, M.; Elsdon, M.; Foti, S. Indirect holographic techniques for determining antenna radiation characteristics and imaging aperture fields. IEEE Antennas Propag. Mag. 2007, 49, 54-67. 
86. Wang, L.; Simpkin, R.; Al-Jumaily, A. Holographic microwave imaging for medical applications. J. Biomed. Sci. Eng. 2013, 6, 823.

87. Wang, L.; Al-Jumaily, A.M.; Simpkin, R. Imaging of 3-D dielectric objects using far-field holographic microwave imaging technique. Prog. Electromagn. Res. B 2014, 61, 135-147.

88. Wang, L.; Simpkin, R.; Al-Jumaily, A.M. Three-dimensional far-field holographic microwave imaging: An experimental investigation of dielectric object. Prog. Electromagn. Res. B 2014, 61, 169-184.

89. Paz, A.V.; Medina, M.A.Y. Holographic Microwave Imaging: Experimental study on spatial distribution of antennas for accurate results. In Proceedings of the IEEE MTT-S Latin America Microwave Conference (LAMC), Puerto Vallarta, Mexico, 12-14 December 2016; pp. 1-3.

90. Fear, E.C.; Hagness, S.C.; Meaney, P.M.; Okoniewski, M.; Stuchly, M.A. Enhancing breast tumor detection with near-field imaging. IEEE Microw. Mag. 2002, 3, 48-56.

91. Saleh, W.; Wright, D.; Slade, P.; Qaddoumi, N. Exploration of breast tumors utilizing noninvasive near-field microwave imaging. In Proceedings of the 2004 Conference on IEEE Precision Electromagnetic Measurements Digest, London, UK, 27 June-2 July 2004; pp. 202-203.

92. Saleh, W.; Qaddoumi, N. Potential of near-field microwave imaging in breast cancer detection utilizing tapered rectangular waveguide probes. Comput. Electr. Eng. 2009, 35, 587-593.

93. Bourqui, J.; Okoniewski, M.; Fear, E.C. Balanced antipodal Vivaldi antenna with dielectric director for near-field microwave imaging. IEEE Trans. Antennas Propag. 2010, 58, 2318-2326.

94. Ravan, M.; Amineh, R.K.; Nikolova, N.K. Two-dimensional near-field microwave holography. Inverse Probl. 2010, 26, 055011.

95. Amineh, R.K.; Ravan, M.; Khalatpour, A.; Nikolova, N.K. Three-dimensional near-field microwave holography using reflected and transmitted signals. IEEE Trans. Antennas Propag. 2011, 59, 4777-4789.

96. Amineh, R.K.; Ravan, M.; Trehan, A.; Nikolova, N.K. Near-field microwave imaging based on aperture raster scanning with TEM horn antennas. IEEE Trans. Antennas Propag. 2011, 59, 928-940.

97. Rahman, A.; Islam, M.T.; Singh, M.J.; Kibria, S.; Akhtaruzzaman, M. Electromagnetic Performances Analysis of an Ultra-wideband and Flexible Material Antenna in Microwave Breast Imaging: To Implement a Wearable Medical Bra. Sci. Rep. 2016, 6, 38906.

98. Shao, W.; Edalati, A.; McCollough, T.R.; McCollough, W.J. A Phase Confocal Method for Near-Field Microwave Imaging. IEEE Trans. Microw. Theory Tech. 2017, 65, 2508-2515.

99. Golnabi, A.H.; Meaney, P.M.; Geimer, S.; Paulsen, K.D. Microwave imaging for breast cancer detection and therapy monitoring. In Proceedings of the 2011 IEEE Topical Conference on Biomedical Wireless Technologies, Networks, and Sensing Systems (BioWireleSS), Phoenix, AZ, USA, 16-19 January 2011; pp. 59-62.

100. Golnabi, A.H.; Meaney, P.M.; Paulsen, K.D. Tomographic microwave imaging with incorporated prior spatial information. IEEE Trans. Microw. Theory Tech. 2013, 61, 2129-2136.

101. Fear, E.C.; Sill, J.; Stuchly, M.A. Experimental feasibility study of confocal microwave imaging for breast tumor detection. IEEE Trans. Microw. Theory Tech. 2003, 51, 887-892.

102. Lai, J.C.Y.; Soh, C.B.; Gunawan, E.; Low, K.S. UWB microwave imaging for breast cancer detectionExperiments with heterogeneous breast phantoms. Prog. Electromagn. Res. M 2011, 16, 19-29.

103. Jiang, H.; Li, C.; Pearlstone, D.; Fajardo, L.L. Ultrasound-guided microwave imaging of breast cancer: Tissue phantom and pilot clinical experiments. Med. Phys. 2005, 32, 2528-2535.

104. Klemm, M.; Craddock, I.J.; Leendertz, J.A.; Preece, A.; Benjamin, R. Radar-based breast cancer detection using a hemispherical antenna array-Experimental results. IEEE Trans. Antennas Propag. 2009, 57, 1692-1704.

105. Klemm, M.; Leendertz, J.A.; Gibbins, D.; Craddock, I.J.; Preece, A.; Benjamin, R. Microwave radar-based differential breast cancer imaging: Imaging in homogeneous breast phantoms and low contrast scenarios. IEEE Trans. Antennas Propag. 2010, 58, 2337-2344.

106. Klemm, M.; Craddock, I.; Leendertz, J.; Preece, A.; Benjamin, R. Experimental and clinical results of breast cancer detection using UWB microwave radar. In Proceedings of the 2008 AP-S IEEE Antennas and Propagation Society International Symposium, San Diego, CA, USA, 5-12 July 2008; pp. 1-4.

107. Bahramiabarghouei, H.; Porter, E.; Santorelli, A.; Gosselin, B.; Popović, M.; Rusch, L.A. Flexible 16 antenna array for microwave breast cancer detection. IEEE Trans. Biomed. Eng. 2015, 62, 2516-2525.

108. Porter, E.; Walls, G.; Zhou, Y.; Popovic, M.; Schwartz, J.D. A flexible broadband antenna and transmission line network for a wearable microwave breast cancer detection system. Prog. Electromagn. Res. Lett. 2014, 49, 111-118. 
109. Afyf, A.; Bellarbi, L.; Riouch, F.; Errachid, A.; Sennouni, M. Flexible Antenna Array for Early Breast Cancer Detection Using Radiometric Technique. Int. J. Biol. Biomed. Eng. 2016, 10, 10-17.

110. Li, X.; Davis, S.K.; Hagness, S.C.; van der Weide, D.W.; Van Veen, B.D. Microwave imaging via space-time beamforming: Experimental investigation of tumor detection in multilayer breast phantoms. IEEE Trans. Microw. Theory Tech. 2004, 52, 1856-1865.

111. Baran, A.; Kurrant, D.; Zakaria, A.; Fear, E.; LoVetri, J. Breast cancer imaging using microwave tomography with radar-derived prior information. In Proceedings of the 2014 USNC-URSI. IEEE Radio Science Meeting (Joint with AP-S Symposium), Memphis, TN, USA, 6-11 July 2014; p. 259.

112. Eleutério, R.; Medina, A.; Conceição, R.C. Initial study with microwave imaging of the axilla to aid breast cancer diagnosis. In Proceedings of the 2014 USNC-URSI IEEE Radio Science Meeting (Joint with AP-S Symposium), Memphis, TN, USA, 6-11 July 2014; p. 306.

113. Grzegorczyk, T.M.; Meaney, P.M.; Paulsen, K.D. Microwave tomographic imaging for breast cancer chemotherapy monitoring. In Proceedings of the IEEE 8th European Conference on Antennas and Propagation (EuCAP 2014), The Hague, The Netherlands, 6-11 April 2014; pp. 702-703.

114. Tivnan, M.; Rappaport, C.; Martinez-Lorenzo, J.A.; Morgenthaler, A. FDFD microwave modeling of realistic, inhomogeneous breast tissue based on digital breast tomosynthesis priors for cancer detection. In Proceedings of the IEEE 2014 40th Annual Northeast Bioengineering Conference (NEBEC), Boston, MA, USA, 25-27 April 2014; pp. 1-2.

115. Obermeier, R.; Juesas, J.H.; Martinez-Lorenzo, J.A. Imaging breast cancer in a hybrid DBT/NRI system using compressive sensing. In Proceedings of the 2015 IEEE International Symposium on Antennas and Propagation \& USNC/URSI National Radio Science Meeting, Vancouver, BC, Canada, 19-24 July 2015; pp. 392-393.

116. Dagheyan, A.G.; Molaei, A.; Obermeier, R.; Martinez-Lorenzo, J. Preliminary imaging results and SAR analysis of a microwave imaging system for early breast cancer detection. In Proceedings of the IEEE 38th Annual International Conference of the Engineering in Medicine and Biology Society (EMBC), Orlando, Fl, USA, 16-20 August 2016; pp. 1066-1069.

117. Dagheyan, A.G. A Near-Field Radar Mechatronics System for Early Detection of Breast Cancer; Northeastern University: Boston, MA, USA, 2016.

118. Dagheyan, A.G.; Molaei, A.; Obermeier, R.; Martinez, A.K.; Lorenzo, J.M. Near-Field Radar Microwave Imaging as an Add-on Modality to Mammography. In New Perspectives in Breast Imaging; Malik, A., Ed.; InTech: London, UK, 2017; Chapter 2, p. 15.

119. Fei, P.; Jiao, Y.C.; Hu, W.; Zhang, F.S. A miniaturized antipodal Vivaldi antenna with improved radiation characteristics. IEEE Antennas Wirel. Propag. Lett. 2011, 10, 127-130.

120. Bourqui, J.; Okoniewski, M.; Fear, E.C. Balanced antipodal Vivaldi antenna for breast cancer detection. In Proceedings of the EuCAP 2007 The Second European Conference on IET Antennas and Propagation, Edinburgh, UK, 11-16 November 2007; pp. 1-5.

121. Molaei, A.; Kaboli, M.; Mirtaheri, S.A.; Abrishamian, M.S. Dielectric lens balanced antipodal Vivaldi antenna with low cross-polarisation for ultra-wideband applications. IET Microw. Antennas Propag. 2014, 8, 1137-1142.

122. Molaei, A.; Dagheyan, A.G.; Juesas, J.H.; Martinez-Lorenzo, J. Miniaturized UWB Antipodal Vivaldi Antenna for a mechatronic breast cancer imaging system. In Proceedings of the 2015 IEEE International Symposium on Antennas and Propagation \& USNC/URSI National Radio Science Meeting, Vancouver, BC, Canada, 19-24 July 2015; pp. 352-353.

123. Rappaport, C. Determination of bolus dielectric constant for optimum coupling of microwaves through skin for breast cancer imaging. Int. J. Antennas Propag. 2008, 2008, doi:10.1155/2008/359582.

124. Buchner, R.; Hefter, G.T.; May, P.M. Dielectric relaxation of aqueous $\mathrm{NaCl}$ solutions. J. Phys. Chem. A 1999, 103, 1-9.

125. Sato, T.; Buchner, R. Dielectric relaxation processes in ethanol/water mixtures. J. Phys. Chem. A 2004, 108, 5007-5015.

126. Lu, Z.; Manias, E.; Macdonald, D.D.; Lanagan, M. Dielectric relaxation in dimethyl sulfoxide/water mixtures studied by microwave dielectric relaxation spectroscopy. J. Phys. Chem. A 2009, 113, 12207-12214.

127. Markarian, S.; Gabrielyan, L. Dielectric relaxation study of diethylsulfoxide/water mixtures. Phys. Chem. Liq. 2009, 47, 311-321.

128. Kavala, A.K. Dielectric relaxation behaviour of glycine in acqueous solution medium in the microwave frequency region. Indian J. Eng. Mater. Sci. 2008, 15, 196-198. 
129. Shinyashiki, N.; Sudo, S.; Abe, W.; Yagihara, S. Shape of dielectric relaxation curves of ethylene glycol oligomer-water mixtures. J. Chem. Phys. 1998, 109, 9843-9847.

130. Joshi, Y.; Kumbharkhane, A. Study of dielectric relaxation and hydrogen bonding in water+ 2-butoxyethanol mixtures using TDR technique. Fluid Phase Equilib. 2012, 317, 96-101.

131. Kaatze, U. Microwave dielectric properties of liquids. Radiat. Phys. Chem. 1995, 45, 549-566.

132. Joshi, Y.; Kumbharkhane, A. Study of heterogeneous interaction in binary mixtures of 2-methoxyethanolwater using dielectric relaxation spectroscopy. J. Mol. Liq. 2011, 161, 120-124.

133. Barthel, J.; Bachhuber, K.; Buchner, R.; Hetzenauer, H. Dielectric spectra of some common solvents in the microwave region. Water and lower alcohols. Chem. Phys. Lett. 1990, 165, 369-373.

134. Saar, D.; Brauner, J.; Farber, H.; Petrucci, S. Ultrasonic and microwave dielectric relaxation of liquid dialkyl carbonates. J. Phys. Chem. 1978, 82, 2531-2535.

135. Tidar, A.; Shafiyoddin, S.; Kamble, S.; Dharne, G.; Patil, S.; Khirade, P.; Mehrotra, S. Microwave dielectric relaxation study of 1-hexanol with 1-propenol mixture by using time domain reflectometry at 300k. In Proceedings of the 2009 IEEE Applied Electromagnetics Conference (AEMC), Kolkata, India, 14-16 December 2009; pp. 1-4.

136. Saar, D.; Brauner, J.; Farber, H.; Petrucci, S. Microwave dielectric relaxation of some lithium salts in dimethyl carbonate. J. Phys. Chem. 1978, 82, 545-552.

137. Undre, P.; Khirade, P.; Rajenimbalkar, V.; Helambe, S.; Mehrotra, S. Dielectric Relaxation in Ethylene Glycol-Dimethyl Sulfoxide Mixtures as a Function of Composition and Temperature. J. Korean Chem. Soc. 2012, 56, 416-423.

138. Kumar, S.; Periyasamy, P.; Jeevanandham, P. Dielectric Relaxation Studies of Amides with 2-methoxyethanol and 2-butoxyethanol Using Time Domain Reflectometry Technique. Int. J. Recent Sci. Res. 2012, doi:10.24327/IJRSR.

139. Bindu, G.; Anil, L.; Vinu, T.; Aanandan, C.K.; Mathew, K. Dielectric studies of corn syrup for applications in microwave breast imaging. Prog. Electromagn. Res. 2006, 59, 175-186.

140. Dagheyan, A.G.; Molaei, A.; Juesas, J.H.; Martinez-Lorenzo, J. Characterization of Two Antipodal Vivaldi Antennas for Breast Cancer Near-Field Radar Imaging. In Proceedings of the 2016 IEEE International Symposium on Antennas and Propagation \& USNC/URSI National Radio Science Meeting, Fajardo, PR, USA, 26 June-1 July 2016.

141. Mathew, T.; Vyas, A.; Tripathi, D. Dielectric properties of some edible and medicinal oils at microwave frequency. Can. J. Pure Appl. Sci. 2009, 3, 953.

142. Hasgall, P.; Neufeld, E.; Gosselin, M.; Klingenböck, A.; Kuster, N. IT'IS Database for Thermal and Electromagnetic Parameters of Biological Tissues. Version 3.0, 1 September 2015. Available online: https: / /www.itis.ethz.ch/virtual-population/tissue-properties/database/tissue-frequency-chart/ (accessed on 11 November 2016). doi:10.13099/VIP21000-03-0.

143. Federal Communications Commission. Evaluating Compliance with FCC Guidelines for Human Exposure to Radiofrequency Electromagnetic Fields; Federal Communications Commission: Washington, DC, USA, 1997.

144. European Commission. Implementation Report on the Council Recommendation Limiting the Public Exposure to Electromagnetic Fields (0 Hz to $300 \mathrm{GHz}$ ); Public Health, European Commission: Brussels, Belgium, 2008.

145. Institute of Electrical and Electronics Engineers (IEEE). Recommended Practice for Determining the Peak Spatial-Average Specific Absorption Rate (SAR) in the Human Head from Wireless Communications Devices: Measurement Techniques—Redline; IEEE Std 1528-2013 (Revision of IEEE Std 1528-2003)—Redline; IEEE: New York, NY, USA, 2013; pp. 1-500.

146. Obermeier, R. Compressed Sensing Algorithms for Electromagnetic Imaging Applications; Northeastern University: Boston, MA, USA, 2016.

147. Obermeier, R.; Martinez-Lorenzo, J.A. A compressive sensing approach for enhancing breast cancer detection using a hybrid DBT/NRI configuration. J. Electromagn. Waves Appl. 2017, 31, 72-81.

148. Tan, D. Modeling the Specific Absorption Rate Distribution of a Smartphone; ANSYS Inc.: Canonsburg, PA, USA, 2012.

149. Shin, H.J.; Kim, H.H.; Cha, J.H. Current status of automated breast ultrasonography. Ultrasonography 2015, 34, 165-172.

150. Erhard, K.; Fredenberg, E.; Homann, H.; Roessl, E. Spectral lesion characterization on a photon-counting mammography system. In Proceedings of the International Society for Optics and Photonics Medical Imaging 2014: Physics of Medical Imaging, Boston, MA, USA, 14-18 September 2014; Volume 9033, p. 90331F. 
151. O'connor, M.K. Molecular breast imaging: An emerging modality for breast cancer screening. Breast Cancer Manag. 2015, 4, 33-40.

152. Henriksson, T.; Joachimowicz, N.; Conessa, C.; Bolomey, J.C. Quantitative microwave imaging for breast cancer detection using a planar $2.45 \mathrm{GHz}$ system. IEEE Trans. Instrum. Meas. 2010, 59, 2691-2699. 